Ciências 



\title{
A criação científica segundo Poincaré e Einstein
}

\author{
MICHEL PATY
}

A Alberto Luiz da Rocha Barros

In memoriam

\section{Confluências}

$\mathrm{H}$

ENRI POINCARÉ e Albert Einstein, apesar das significativas divergências de suas respectivas filosofias do conhecimento científico (o primeiro conciliava a seu modo elementos de empirismo e convencionalismo, enquanto o segundo professava um realismo e um racionalismo críticos), tinham em comum a convicção (entre outras), de central importância para o assunto que aqui nos ocupa, de que as idéias científicas, na elaboração das teorias físicas e matemáticas, são "construções livres do pensamento". Neste sentido, entendiam que elas não são induzidas de maneira lógica e unívoca, necessária e compulsória, a partir dos dados da experiência, e além disso que elas não estão inscritas numa estrutura inata ou a priori do pensamento. É nesse espaço de liberdade que entra a idéia da criação no trabalho científico que conduz à descoberta. Da maneira mais clara, Poincaré e Einstein, ambos insistiram nesse aspecto que era, para eles, a característica mais importante da atividade do conhecimento, e que se situava efetivamente no centro de suas epistemologias.

É importante, de fato, apreender diretamente, na medida do possível, as relações efetivas entre os problemas oriundos da filosofia do conhecimento e a atividade do conhecimento em si. O conhecimento científico não se reduz a seus conteúdos seguros, a suas proposições e seus efeitos; compreende em suas dimensões o próprio trabalho do pensamento que o estabelece. Sob este aspecto, o testemunho de criadores científicos excepcionais como Poincaré e Einstein é evidentemente insubstituível. É tanto mais significativo que ambos esses cientistas tenham sido verdadeiros filósofos, de modo que sua feição espiritual os levava a pôr filosoficamente para si próprios questões de natureza filosófica (Paty, 1993; $[\mathrm{a}] ;[\mathrm{c}])$.

No domínio do pensamento científico o tema da invenção, da "criação", surgiu de fato diretamente relacionado a todas as outras questões filosóficas postas pela ciência enquanto "pensamento", atividade intelectual eminentemente racional, que tem a sua sede, antes de qualquer comunicação ou juízo consensual, em 
inteligências singulares, subjetivas. Considera-se, em particular, que a atividade criadora do pensamento racional é condicionada pela inteligibilidade dos "objetos" que são propostos à sua compreensão e a seus julgamentos. A este respeito, não se pode deixar de remeter, ainda que brevemente, a Descartes e aos filósofos que depois dele se preocuparam com as condições da possibilidade de um conhecimento racional, seja para criticá-las, como Hume, seja para estabelecê-las, como Kant.

Contudo, a filosofia - a dos filósofos e a dos cientistas (ou savants) - em geral não se preocupou tanto com a dimensão criadora do pensamento científico: de um lado, provavelmente, graças a uma concepção de ciência que via esta última como as formas já acabadas, "verdadeiras" ou "certas", e não como um trabalho em constante reelaboração; mas também, sem dúvida, devido à aparente contradição entre o interesse por verdades objetivas e a atribuição de importância às subjetividades que são sua fonte (e que no fundo não deixam de ser sua sede). Evocaremos, então, certas doutrinas filosóficas anteriores ao período que nos interessa, o de Poincaré e Einstein. Por outro lado, paralelamente à relativa indiferença filosófica por tudo o que concerne à invenção e à criação científicas, constata-se ao longo do século XIX, com os novos avanços dos conhecimentos científicos, notadamente na matemática e na física, o estabelecimento de condições intelectuais propícias para a consideração desse problema.

Tais apresentações permitirão que vejamos como os pensamentos de Poincaré e Einstein sobre a criação científica se situam na confluência dessas novas perspectivas (em suas lições sobre a natureza das proposições da ciência) com o pensamento crítico da filosofia, ainda que este apontasse para outros projetos. A aguda consciência do sentido de suas próprias pesquisas lhes terá favorecido o olhar reflexivo, levando-os a questionar o trabalho de seu próprio pensamento, fazendo a junção, ao que parece ainda inédita, entre a experiência criadora e a reflexão sobre suas condições filosóficas. Depois da apresentação dessa experiência tal como eles próprios a puderam relatar, examinaremos como a relacionaram a suas respectivas concepções filosóficas, testemunhando afinal em favor da inscrição racional da invenção e da criação científicas, e portanto em favor de seu pleno alcance filosófico.

\section{Invenção e inteligibilidade}

Os filósofos, e entre eles freqüentemente aqueles que foram ao mesmo tempo pesquisadores científicos (os “cientistas-filósofos"), interessavam-se sobretudo, a propósito da ciência, pela natureza desta sob a forma daquilo que determina a sua verdade e aponta o erro. Sendo criadores eles próprios, pareciam dar bem pouca atenção a seus próprios atos de invenção ou descoberta enquanto atos de criação, e em geral não se consideravam como tais. Os problemas que os preocupavam eram principalmente a compreensão e a inteligibilidade das proposições enunciadas, bem como a sua justificação lógica e racional. 
O próprio Descartes é um bom testemunho do movimento desse pensamento filosófico, cioso de alcançar a justificativa das razões em busca de verdades, sem se preocupar o bastante com as circunstâncias das descobertas e com as vias pelas quais o espírito chega a forjar as certezas e se deixa iluminar pela evidência. Para ele, a razão deveria suspeitar da imaginação, e a doutrina do conhecimento evitar que esta última tomasse a dianteira. Ainda assim, Descartes, mais que qualquer outro, dava grande importância à intuição pois, a seu ver, era através dela que se produzia a iluminação da evidência que constituía, para ele, o momento da compreensão, prolongado pela reflexão que apela à dedução e à memória, e se relaciona à evidência pela constituição de certezas. Mas tratava-se de uma intuição racional entendida antes de mais nada como uma função sintética do entendimento (Paty, 1997).

Nas Regras para a direção do espirito, Descartes estabeleceu aquelas que para ele deveriam ser as condições da inteligibilidade; elas incluíam as condições da invenção (que a seu ver eram sobretudo da ordem da descoberta), já que toda compreensão por parte de um sujeito é, em certa medida, reinvenção; assim, ele as remetia desde logo ao enunciado do método (Descartes, 1628). A ponto de suster a redação das Regulae, deixando-as inacabadas, para expor quase dez anos depois um Discurso do método plenamente organizado (1). Com isso ele se voltou para a experiência do conhecimento, buscando compreender aí os fundamentos da certeza a que essas regras conduziam. Os objetos desse conhecimento, sempre portadores de elementos novos (para nós), eram considerados como já presentes em toda eternidade: ao descobrir, alcançamos a verdade, de essência eterna e divina.

Descartes, portanto, não negava a invenção como capacidade do intelecto, mas pretendia submetê-la a critérios normativos, ao "método". Neste sentido, sua atitude com relação às suas próprias inovações é característica. Se ele declarava que as curvas mecânicas (ou transcendentes) não pertenciam à sua Geometria (Descartes, 1637b), livro que acompanhava o Discurso do método como sua ilustração, isso era devido à definição por ele proposta das curvas geométricas (ou algébricas), a saber, que poderiam ser engendradas por uma só transformação finita e contínua de um ponto a outro a partir de uma linha reta ou de um círculo. Mas isto não o impediu de estudar as curvas mecânicas - por exemplo, a ciclóide (2) -, dando mostras da maior inventividade, inclusive desenvolvendo reflexões antecipadoras de certos aspectos do cálculo diferencial e integral.

Na verdade, para ele não se tratava de descoberta, mas sobretudo de experiência, no sentido de fazer a experiência, ou o exercício, da razão. A descoberta propriamente dita que ele mesmo reconheceu foi a do método. O que a seu ver merecia a qualificação de descoberta ou de invenção era, pode-se dizer, da ordem do metacientífico, ou seja, do filosófico (tomando estes termos no seu sentido atual). E sua iluminação no outono de 1619, determinante de sua vocação, foi precisamente desta ordem, transcendente ao generalizar pela filosofia as suas inovações matemáticas (3). 
Se temos privilegiado Descartes, é porque ele foi, entre os pensadores clássicos, aquele que primeiro se preocupou com a atividade do pensamento racional no âmbito da singularidade de uma subjetividade (Paty, 1997). Seria necessário mencionar em seguida as doutrinas que se dedicaram a descrever os processos cognitivos ou a estabelecer as suas condições, incluindo as impressões dos sentidos e da sensibilidade na formação das idéias, de Locke a Condillac, Berkeley, Diderot, d'Alembert, Hume, Kant... e aos pensadores seguintes, do século XIX (de Ampère a Helmholtz, Mach, Pierce, W. James...), até os dois autores que ora nos ocupam.

Mas não é a nossa intenção fazer uma história das idéias sobre a criação científica. Notemos apenas que os filósofos que se interessaram pela criação em geral se reportaram às atividades que provêm diretamente da imaginação, ou seja, das artes, em conformidade, afinal de contas, com a classificação tradicional das atividades mentais segundo as três "faculdades da alma": memória, razão, imaginação (4). É verdade que Diderot, por exemplo, situava também a imaginação entre as primeiras fontes do pensamento das ciências da natureza, mas ao preço de favorecer exclusivamente as ciências empíricas, apoiando-se sobre o recurso às analogias, que levavam à indução baconiana, depreciando a matemática $\mathrm{e}$ a física racional, que ele considerava um "domínio acabado" (5).

Como regra geral, no século XIX as ciências eram consideradas em função de seus objetivos concebidos segundo suas "relações verdadeiras", o que subentende a idéia de uma "classificação natural" (Ampère, 1834: 4), e essa preocupação quase exclusiva relegava a um segundo plano, ou mesmo ocultava, a questão das vias pelas quais elas eram trazidas à luz através do trabalho do pensamento dos cientistas. Os conteúdos científicos importavam antes de mais nada, e a ciência era freqüentemente concebida de modo normativo, conforme um esquema de pensamento ressaltado e sistematizado pela filosofia positivista (Comte, 18301842). Interessando em particular aos conteúdos da matemática e da física, subjacente à idéia da descoberta, estava a naturalidade da coisa descoberta, já presente em potencial, mas ainda não identificada, que nos é dada, ao termo de um processo de pensamento, e que sobretudo não é realmente inventada. Ou, caso fosse, não o seria senão a título de pensamento ancilar de uma ordem que o ultrapassava, e era esta a ordem que interessava à filosofia.

Ou ainda, uma vez que seus conteúdos de conhecimento, seus saberes, eram tidos como objetos de invenção de uma subjetividade, era preciso esforçar-se - tal era o principal objetivo da ciência - no sentido de eliminar esse "coeficiente individual que se encontra em todo indivíduo no ato de conhecimento", mesmo que isto signifique admitir que no final das contas sempre resta na verdade da ciência uma irredutível dimensão humana (Rey, 1911: 34).

O interesse pelos processos mentais com relação às impressões dos sentidos e pela descrição psicológica das funções intelectuais aumentou consideravelmente 
na segunda metade do século XIX, no bojo do desenvolvimento de pesquisas sobre a fisiologia da percepção - notadamente com Hermann von Helmholtz (1882-1895; 1921; 1977) -, sobre a psicofisiologia das sensações - com Ernst Mach (1986) -, e o advento da psicologia, à qual de bom grado se referem tanto os cientistas quanto os filósofos - William James, Théodore Ribot (6), Henri Bergson, seu discípulo Edouard Le Roy etc. Essa circunstância contribuiu também, inegavelmente, para favorecer a distensão epistemológica entre o conceitual e o empírico, como se vê, por exemplo, nas epistemologias dos próprios Helmholtz e Mach. Favoreceu, da mesma forma, sobretudo pelo viés da psicologia, o interesse pelos processos de invenção no pensamento comum e no pensamento científico.

No entanto, o que mais atraía atenção eram os mecanismos do pensamento considerados por si sós, em detrimento dos efeitos dessa invenção sobre o conhecimento. A maioria desses pensadores professava uma filosofia empirista ou pragmatista, e, embora concebessem a existência de uma invenção de formas artificiais no nosso conhecimento, estas para eles permaneciam secundárias com relação à prática e à ação. As teorias não eram mais que folhas provisórias da árvore dos conhecimentos - foi mais ou menos assim o que escreveu Ernst Mach, neste ponto preocupado sobretudo com a crítica dos conceitos indevidamente erigidos em absolutos (Mach, 1883; 1886; 1906).

Quanto a William James (1907; 1909; 1912; 1917), filósofo do pragmatismo puro, do "empirismo radical da prática”, na expressão de Rey (1911: 79), era por equívoco que o acusavam de pôr a utilidade acima do conhecimento. Bergson, que justamente lhe atribuía a intenção contrária, reconhecia em sua doutrina a originalidade de ver, numa "verdade nova", uma "invenção", ao contrário das outras, que veriam aí tão somente uma "descoberta" (7). No que concerne a James, essa concepção se relaciona em parte com uma concepção particular de verdade. Conforme sua doutrina, para retomar as palavras de Bergson (1934 in 1959: 1447), “a verdade de ordem intelectual é uma invenção humana que tem o efeito de utilizar a realidade, em vez de a ela nos introduzir". Com relação ao nosso problema, essa idéia de uma verdade que se constitui para frente, submetida às "correntes da realidade", tende a esvaziá-la de um sentido preciso numa dada situação, de modo a fazê-la perder, em particular, qualquer possibilidade de ser caracterizada racionalmente.

A filosofia de Bergson, não obstante a sua essência inteiramente distinta e, além disso, a sua insatisfação perante tal concepção de realidade, é consonante com o pragmatismo puro de James sob muitos aspectos. Ambos têm em comum particularmente um antiintelectualismo, e as verdades que importam para eles são mais sentidas e vividas do que pensadas. A filosofia bergsoniana da consciência, fundada na experiência interior, tem um papel importante na invenção, na intuição e na imaginação criadoras. Se Bergson (1934 in 1959: 1445) criticava a concepção kantiana de uma verdade já dada na manifestação do real, ele via na 
atividade mental criadora antes de mais nada um exemplo dessa "crescente materialização do imaterial que é característica da atividade vital", sendo portanto um potencial da natureza em devir (8). Entretanto, talvez mais que os outros, apesar de sua minimização das idéias teóricas, Bergson se atinha aos efeitos do esforço mental voluntário sobre a formação e a organização das idéias. Retomaremos adiante algumas de suas observações, de acordo com aquilo que veremos em Poincaré e Einstein.

O filósofo Abel Rey, por sua vez, falava da "invenção da ciência”, em particular da "invenção matemática", e da matemática como "invenções primordiais da razão teórica", insistindo sobre a distância entre "tamanho potencial de possibilidades, tamanha criação de rela-

... ele retomava as concepções de Poincaré sobre a matemática como “criação arbitrária do espírito" ... ções virtuais" e uma ciência do real (Rey, 1911: 71-72). De fato, ele retomava as concepções de Poincaré sobre a matemática como "criação arbi-

trária do espírito, (...) a mais impressionante manifestação de sua própria fecundidade", que este último "inventou" "por ocasião da experiência" (Rey, 1911: 76). Apresentando a matemática tal como a temos, enquanto concepção arbitrária do espírito, usada na experiência e assim desenvolvida na direção que conhecemos, segundo a concepção de Poincaré, Rey pretendia sublinhar a diferença entre esta última e aquela dos pragmatistas: para Poincaré, a ciência e a razão vêm em primeiro lugar e "ultrapassam de muito o campo da utilidade" (9).

Outros filósofos também deram lugar a estas dimensões, como Émile Meyerson (1931), que se dedicou a penetrar "o enigma do caminho do pensamento" na atividade científica, bem como no pensamento comum. Contemporâneo de Einstein, pode-se dizer que Meyerson encerra o período aberto pela filosofia sobre a invenção das idéias científicas. Também a ele voltaremos adiante, em nossas conclusões.

O universo filosófico tinha assim aberto o caminho para a idéia de uma invenção das formas teóricas, mas raramente concebendo que se poderia tratar aí de um campo de investigação para a própria filosofia. Viam-na sobretudo como uma dimensão ou uma circunstância que deveria ser levada em conta, seja para insistir sobre a sua fragilidade ou o seu caráter relativo, seja para reforçar as regras da cientificidade, tendo esta perdido, por assim dizer, as suas bases naturais (10). É assim que, na linhagem do positivismo e do pragmatismo, mas associados ao logicismo, o empirismo e o positivismo lógicos que floresceram no século XX, bem como seus herdeiros, dissidentes ou não, tentaram esvaziar da filosofia a invenção e a criação científicas como momentos irracionais, necessários, mas 
incontroláveis e passageiros (11). Outros construíram então para o conhecimento, sobre essa no man's land filosófica, doutrinas da a-racionalidade (12). Mas essa seria uma outra história.

\section{O distanciamento dos objetos de pensamento}

Não foi por acaso que a tomada de consciência sobre a invenção na atividade científica só teve início no século XIX (e bem mais para os seus finais): sem dúvida, foram decisivos os acontecimentos que a partir de então se deram na matemática e na física. Com efeito, foi a época em que se afrouxou o laço até então apertado entre a matemática e a natureza, com a invenção das matemáticas que pareciam contradizer a "evidência" da experiência comum - tais como as geometrias não-euclidianas - ou ainda puramente abstratas ou formais.

A física, a partir do mesmo período, também se desenvolveu através da elaboração de teorias cada vez mais matematizadas, recorrendo a grandezas de expressão simbólica abstrata à maneira matemática, cujo caráter de construção tornava-se mais visível do que nas formulações anteriores. A constituição da física teórica nos seus diversos domínios (a ótica, a eletricidade, o magnetismo, a termodinâmica), pela sua matematização analítica ao modo da física matemática, de que a Mecánica analítica de Lagrange (1788) representava a mais perfeita expressão para a mecânica, deixava entrever com crescente evidência a distância entre os domínios da experiência imediata e a abstração da teoria formalizada. A mecânica de Hamilton retomava a de Lagrange sob uma roupagem teórica e conceitual bem diferente, na qual as grandezas não correspondiam mais a conceitos fundados sobre noções comuns. Passou-se a admitir como princípio físico fundamental uma propriedade aparentemente muito formal, como o princípio do mínimo de ação na sua expressão variacional dada por Hamilton.

Mesmo os dados fenomênicos mais importantes escapavam à operação de conhecimento direta, demandando a constituição de abstrações intermediárias, conceitos ou grandezas inseparáveis da matemática usada para concebê-las, tais como as noções de campo, energia, potencial...

Em termodinâmica, se o primeiro princípio (a conservação da energia) ainda estava conforme as concepções anteriores da física, fundadas sobre a mecânica, o segundo, formulado aproximadamente ao mesmo tempo, revelava a sua natureza claramente abstrata e interpretativa. O segundo princípio da termodinámica, a saber, o aumento da entropia com o tempo nos sistemas fechados - exprimindo a irreversibilidade das transformações - apresentava-se sob uma forma afastada da intuição física imediata - antes de sua tradução nos termos da mecânica estatística (13). Daí em diante já não se tratava de uma descrição direta dos fenômenos tais como a mecânica ainda os concebia. A entropia, com efeito, era uma função construída, exprimindo uma propriedade estrutural entre as grandezas, difícil de 
conceber simplesmente, demandando uma interpretação física que não parecia direta nem evidente como era o caso, pensava-se, de outros conceitos e princípios da física.

Mas, também estes últimos eram então questionados, assim como os da matemática, mesmo os mais geralmente aceitos, como por exemplo, na física, o espaço e a geometria, o tempo e a simultaneidade, ou os princípios da mecânica newtoniana. Notava-se que eles eram modificáveis e passíveis de evolução: já não eram concebidos como absolutos e naturais, percebendo-se o seu caráter de construções do pensamento. Na matemática, evocaremos ainda a noção de conjunto, que parecia muito abstrata, e que se revelaria de considerável importância: também o foi para o pensamento matemático e epistemológico de Poincaré.

Desde então se pôs o problema da natureza desses conceitos e de suas proposições e princípios, de seu estatuto. Para uns, eles se reduziam a proposições empíricas. Para outros, tratava-se de proposições de caráter racional, mas que já não eram a priori e imutáveis. Elas eram racionais enquanto propostas pelo pensamento para estruturar os dados da experiência, mas sempre seria possível reformulá-las. Quanto ao seu estatuto propriamente dito, restava optar se eram criações do pensamento a partir ou não dos dados primários, hipóteses ou seleção de convenções.

Não era preciso muito mais para se pensar que, no fundo, todos os elementos teóricos, inclusive os que pareciam mais "naturais", fossem, e assim eram, na verdade desde sempre, construídos mentalmente sem que tivessem sido jamais dados em correspondência direta com os objetos e os fenômenos do mundo físico. Pense-se no tempo e na duração, no espaço contínuo, no ponto material sem dimensão, e em outros conceitos do gênero, expressos de modo quantitativo exato por grandezas matemáticas adequadas. Tais abstrações são elaborações do pensamento, postas em correspondência com os elementos supostos do mundo real, e justificadas pelo êxito dessa relação. Esta correspondência, porém, não diz respeito aos elementos isolados, teóricos por um lado, factuais por outro, mas aos sistemas que formam esses elementos através de suas relações mútuas, a saber, para os elementos conceituais, a teoria própria, e, para os elementos factuais, o dado da experiência (este também global) apropriado a essa relação.

Assim, as teorias passam a ser construídas, inventadas e postas por uma decisão do pensamento. Tal decisão, decerto, é orientada, no caso da física, para uma representação descritiva e explicativa dos fenômenos da natureza e, no caso da matemática, para a consistência interna de seus conteúdos próprios. Em outras palavras, a construção, que resulta de uma invenção, é, nos dois casos, submetida a restrições. Mas nem por isso deixa de ser uma invenção, uma criação.

Apesar de a abertura em direção a tais idéias, em razão de evidências adquiridas, esse campo de reflexão tem sido muito pouco estudado pela filosofia no 
curso do século que agora termina, predominantemente inspirada, no que diz respeito ao conhecimento, no positivismo e no empirismo lógicos. Ainda que admitindo a existência do momento de invenção, de criação, no processo de elaboração científica, consideravam-no como algo que escapa ao racional e importa somente para a psicologia (ou, mais tarde, para a sociologia). A distinção entre um "contexto de descoberta" e um "contexto de justificação", este considerado como o único digno de atenção por parte da filosofia, permaneceu largamente aceita até bem recentemente. Mesmo Imre Lakatos considerava necessário "reconstruir racionalmente" os conteúdos científicos depois de sua descoberta, o que significava considerá-los como muito pouco racionais no seu surgimento (Lakatos, 1978). Assim, a invenção científica escapava totalmente à filosofia do conhecimento (14).

Não era esta a posição de Poincaré, ainda que os positivistas lógicos o considerassem um de seus principais inspiradores, nem a de Einstein, que sempre insistiu no aspecto de criação livre (no sentido lógico) pelo pensamento humano de proposições e conceitos científicos. Nossos dois cientistas-filósofos, neste sentido, são exceções. Em todo caso, foi no contexto indicado de tomada de consciência epistemológica da distância entre as proposições teóricas e os dados "imediatos" que eles desenvolveram suas próprias concepções sobre a invenção e a criação científicas.

\section{Poincaré e a invenção das funções fuchsianas}

Não é muito freqüente que os cientistas, em seu trabalho de pesquisa, mesmo quando se preocupam com o significado de idéias produzidas por seu pensamento, voltem atrás para repassar o processo de invenção e o momento criador que eles experimentaram, tentando descrevê-los ou deles prestar contas. Em geral, preferem explicar as suas descobertas reorganizando-as de outra maneira, que lhes pareça racionalmente justificada. "Substituem o andamento real de seu pensamento e suas experiências por outro que posteriormente lhes parece mais lógico e oportuno", observou o físico Edmond Bouty, e, concluindo: “Já fazem daí matéria de ensinamento" (Bouty, 1920: 56). O que conta, para a maioria, é o edifício ulteriormente reestruturado que resulta de obras provisórias.

Mesmo Poincaré, que em contraste com essa posição afirmava que o cerne da sua filosofia do conhecimento era o tema da invenção científica (Poincaré, 1913), raramente se dedicou ao exercício de tentar repassar a gênese de suas idéias. Ele o fez pelo menos a propósito de uma de suas maiores descobertas matemáticas, a das funções fuchsianas; a descrição que ele deixou a respeito se tornou célebre. É verdade que ele a apresentou em conferência na Sociedade de Psicologia de Paris - a psicologia, juntamente com a sociologia, ocupavam então o proscênio, como ciências humanas jovens e promissoras, e ainda não destacadas da filosofia. Já eram, no fundo, a filosofia e a psicologia cognitivas... 
Poincaré procurou, assim, sob o título "A invenção matemática”, analisar a série de pensamentos que o conduziu a imaginar esses novos seres matemáticos (15). Ainda que em parte psicológica, a descrição não é estranha à pesquisa racional de uma abordagem filosófica. Tentaremos, a partir desse relato, seguir passo a passo a racionalidade na invenção, ou a criação científica, esclarecendo-a em seguida através das concepções epistemológicas que Poincaré expôs alhures.

O relato de Poincaré apresenta uma série de várias fases de um trabalho mental antes consciente, depois inconsciente, posteriormente novamente consciente e de novo inconsciente etc. Ressaltemos desde já que, mesmo nos momentos de trabalho inconsciente do espírito, esse trabalho é preparado por uma atividade racional anterior.

O processo toma o seu ponto de partida num problema que Poincaré colocou inicialmente, a partir da leitura dos trabalhos de Lazarus Fuchs, que lhe fora recomendada por seu professor Charles Hermite, assim como na questão posta em concurso em 1878 pela Academia de Ciências de Paris, sobre a teoria das equações diferenciais lineares de uma variável (16). Poincaré pensava a princípio que uma certa classe de funções, como soluções de equações diferenciais lineares, não poderia existir: essa formulação do problema determinou o primeiro momento de um trabalho voluntário e consciente, mas que não parecia chegar a uma conclusão: "Desde há quinze dias, eu procurava demonstrar que não poderia haver qualquer função análoga à que depois eu viria a chamar de funções fuchsianas. (...) Eu experimentava um grande número de combinações e não chegava a nenhum resultado" (Poincaré, 1908c in 1918: 50).

Depois dessa fase de trabalho consciente e intensa reflexão, sobreveio outra, correspondendo a um estado de "consciência subliminar", em seus próprios termos, depois de uma noite de insônia consecutiva à ingestão de café preto... A descrição torna-se então psicológica, mas nem por isso deixa de remeter ao movimento do pensamento em geral: este se ocupava de escolher as combinações de idéias, e acabou evidenciando "a existência de uma classe de funções fuchsianas, derivadas da série geométrica". Poincaré as remeteu em seguida a outras classes de funções que formam as atualmente chamadas "funções automórficas".

Poincaré indica ter feito, depois da fase do "estado não-consciente" de seu pensamento, a experiência de um tipo de desdobramento, como se o seu $\mathrm{eu}$, consciente, mas inativo, observasse o seu eu inconsciente (coisa rara, no dizer de Hadamard (1945), que viria a comentar esse excepcional testemunho). Assim, ele via seu próprio eu como a sede de uma atividade viva e desordenada, as idéias (cuja natureza não é especificada no relato) surgindo em profusão e se contrapondo umas às outras. "Eu as sentia como que colidindo entre si”, conta ele, "até que duas delas se engancharam, por assim dizer, formando uma combinação estável" (Poincaré, 1908c, 1918: 62-63). Na manhã seguinte, tinha estabelecido a existência das funções fuchsianas derivadas da série hipergeométrica, que ele logo 
descreveria do seguinte modo: "A função fuchsiana é para a geometria de Lobatchewski o que a função duplamente periódica é para a de Euclides" (Poincaré, 1890b). Uma segunda fase, longa, de trabalho consciente, levou-o em seguida à descoberta de uma outra classe de funções transcendentes, as séries e funções tetafuchsianas, generalizando uma propriedade particular das funções elípticas.

Seguiu-se a esse período uma nova experiência de descoberta imediata e fortuita, ligada a um trabalho inconsciente. Durante uma excursão geológica no caminho de Caen a Coutances, quando pensava em coisa completamente diversa, ao subir no estribo de um ônibus, como relatou, “ocorreu-me a idéia, sem que aparentemente nada em meus pensamentos anteriores me preparasse para isso, de que as transformações de que eu me tinha utilizado para definir as funções fuchsianas eram idênticas às da geometria não-euclidiana" (Poincaré, 1908c, 1918: 51-52). Foi uma certeza imediata, que não atrapalhou a conversação logo retomada e que ele pôde mais tarde verificar à saciedade. Um terceiro período de trabalho sobre tema bem diferente (um problema de aritmética), sem maiores resultados, foi mais uma vez seguido de uma iluminação súbita, com a certeza de que "as transformações aritméticas das formas quadráticas ternárias indefinidas eram idênticas às da geometria não-euclidiana". Ele concebeu assim uma generalização de funções fuchsianas para além da série hipergeométrica. Uma última dificuldade então o deteve, também resolvida no termo de um processo inconsciente da mesma natureza que os precedentes (Poincaré, 1908c, 1918: 51-52).

Tal como é relatado, o trabalho do pensamento nas fases "inconscientes semiconscientes" fica bastante obscuro, o que na verdade nada tem de surpreendente. As "idéias que se engancharam" são proposições novas, sem equivalente anterior: elas ganham aqui, como em outros relatos e análises de experiências de compreensão ou criação (17), a forma de símbolos ou signos, como diria mais tarde Albert Einstein, imagens mentais abstratas servindo como elementos do pensamento que joga ao combiná-las, num jogo que pretende "ser análogo a certas conexões lógicas que são objeto de pesquisa" (entre os conceitos que os signos representam) (Einstein, 1945).

Antes de retomar o relato de Poincaré, destacamos que as novas funções transcendentes, "automórficas", fornecem as soluções para numerosas equações diferenciais lineares algébricas, ou seja, com coeficientes racionais. A construção dessas funções se deu por extensão de propriedades das funções obtidas a partir da propriedade das equações correspondentes, de respeitar certos grupos de transformações.

Completemos agora esse relato de uma "invenção matemática" pelo exame de análises epistemológicas no qual Poincaré apresentou as proposições da matemática (e também da física), que esclarecem mais profundamente os "caminhos da racionalidade" na criação científica que ora investigamos. Mas, antes, devemos nos ater a uma outra experiência de "invenção", desta vez na física, acompanhan- 
do o processo através do qual Einstein foi levado a estabelecer a teoria da relatividade, que apoiaremos também, depois, com suas análises epistemológicas. Assim cruzando os fios desse "paralelo", poderemos apreender melhor o parentesco entre essas experiências intelectuais e também entre suas concepções correspondentes sobre elementos dos atos de "criação racional".

\section{Einstein e a invenção das teorias da relatividade}

Einstein formulou sua teoria da relatividade em dois momento, que correspondem a duas formas: a teoria da relatividade restrita, alcançada em 1905 (mas "ruminada" ao longo de quase dez anos); e a teoria da relatividade geral, cuja primeira idéia the ocorreu em 1907, e que foi apresentada em sua forma acabada em 1915 (18). Essas duas etapas de sua teoria, que correspondem de fato a duas teorias distintas, ainda que a segunda possa ser vista como um prolongamento ou uma radicalização da primeira, constituem invenções científicas no pleno sentido da expressão. Não pretendemos aqui analisá-las completamente, enquanto tais, dando conta do processo de sua gênese em toda a sua complexidade: seria tarefa difícil, quiçá impossível, se a pretendêssemos exaustiva, e os aspectos psicológicos, em particular, permanecerão inacessíveis. Limitar-nos-emos a investigar aí os elementos significativos da racionalidade própria a esse trabalho do pensamento, bem como o "salto lógico" que constitui a criação científica.

A criação, mesmo quando se dá no domínio científico, transcende a racionalidade linear tanto quanto a lógica, e mesmo somente a partir dos pontos de vista filosófico ou epistemológico, não devemos nos ater a estas da maneira como as poderíamos reconstituir depois - com todos os sedimentos de interpretações e reestruturações teóricas. $\mathrm{O}$ aporte do trabalho de Einstein nos dois casos era, tal como os problemas que ele estudava, de natureza racional, como o foi também a sua resposta particular (e o mesmo vale, em geral, para as invenções científicas de outros pesquisadores). Toda a questão está em saber se o caminho da criação que vai da formulação do problema até a sua solução é também dessa natureza, e até que ponto, bem como se é possível seguir o fio dessa racionalidade.

No que diz respeito à gênese da relatividade restrita, da qual sabemos ter sido elaborada a partir de dificuldades da teoria eletromagnética, ainda que seu aporte tenha mais tarde ultrapassado essa teoria em particular, o próprio Einstein apresentou diversas vezes preciosas indicações, não exaustivas, mas coerentes entre si. Em suas "Notas autobiográficas", redigidas em 1946, ele indica como "na época em que [ele] era estudante, o tema que mais [o] fascinava era sem dúvida a teoria de Maxwell" (19). Desde seu segundo ano no Polytechnicum de Zurique, ele "reencontr[ou] o problema da luz, do éter e do movimento da Terra", problema que nunca mais o abandonaria. Também se sabe, através de outra reminiscência, mais antiga e de difusão restrita (trata-se de uma conferência pronunciada em 1922, em Kioto, no curso de sua viagem ao Japão, e só publicada em inglês há 
bem pouco tempo), como lhe ocorreu a idéia da teoria da relatividade. "Foi há cerca de dezessete anos", declarou ele em 1922, "que a idéia de tentar desenvolver o princípio da relatividade me ocorreu ao espírito" (Eistein, 1922). Essa idéia originou-se "no problema da ótica dos corpos em movimento". Tratava-se do problema do éter e da possibilidade de demonstrar o movimento da Terra com relação a este.

Dispomos, além disso, de alguns raros testemunhos contemporâneos diretos, como cartas a amigos guardadas ou redescobertas, que confirmam essa preocupação: podemos acompanhar nessa correspondência - a partir de setembro de 1899, a Mileva Maric, sua futura esposa, depois em 1901 a seu colega Marcel Grossmann, em seguida a Michele Besso, o amigo do Bureau des brevets - o interesse constante de Einstein pelos problemas que o conduziram à teoria da relatividade restrita em 1905 (20). Aludindo mais tarde a esse período, ele ressaltaria a convicção que tinha na época de que, em face dos problemas da eletrodinâmica, "somente a descoberta de um princípio formal para o movimento", a exemplo da termodinâmica, poderia conduzir "a resultados seguros" (Einstein, 1946, grifo meu).

Também sabemos que um fenômeno físico específico tem um lugar estratégico na reflexão e no encaminhamento das idéias de Einstein: "O fenômeno da indução eletromagnética me permite formular o postulado de um princípio de relatividade (restrita)" (Einstein, 1946, grifo meu). A importância desse fenômeno em seu pensamento é confirmada por outros textos (21): ele constitui uma espécie de arquétipo da relação entre os fenômenos eletromagnéticos e a relatividade dos movimentos. Em resumo, o campo magnético e o campo elétrico exercem um sobre o outro uma ação recíproca cujo efeito resultante é sempre o mesmo, não importando qual dos dois é posto em movimento e qual permanece em repouso. No entanto, observou Einstein, a teoria eletromagnética então disponível - a de Maxwell e Lorenz - explicava o surgimento de uma corrente no circuito eletromagnético fechado por dois processos diferentes segundo cada um dos casos: o éter em repouso absoluto, lugar e apoio suposto desses campos, introduzia de fato uma assimetria na natureza dos fenômenos (indução magnética num caso, força eletromotriz no outro).

"A idéia de que estivessem em jogo dois casos essencialmente distintos era para mim insuportável”, escreveu Einstein (1946): não poderia ser senão uma diferença de pontos de vista, e não uma diferença real. A seus olhos, a teoria tratava de fenômenos físicos reais, e deveria partir de um ponto de vista particular sobre eles. Sua formulação do problema teórico estava, portanto, orientada por um programa de objetividade que, num certo sentido, sobredeterminava o seu pensamento físico em relação a uma simples preocupação com os dados empíricos e as equações (quer dizer, com aquilo que hoje é freqüentemente chamado de uma modelização). Mas nem por isso ela deixava de pertencer ao campo da 
racionalidade. $\mathrm{O}$ confronto entre a exigência metateórica (que, de fato, entranha a sua concepção mesma da teoria) e o estado de coisas encontrado fazia com que ele assim explicitasse duas idéias teóricas correlatas e expusesse o seu caráter fundamental: o de um princípio de relatividade estendido da mecânica ao eletromagnetismo, e o de uma invariabilidade das leis dos movimentos relativos. Não se nota aqui nada além de uma linha de raciocínio conscientemente percorrida, que estabelece as condições de uma formulação particular - original - das dificuldades da teoria eletromagnética (22): a saber, em final de contas, o confronto entre duas proposições físicas de cunho teórico tomadas como princípios: o princípio da relatividade e o da constância da velocidade da luz (expressão, para Einstein, daquilo que a teoria eletromagnética de Maxwell tem de mais fundamental).

Do confronto das duas proposições surgiu a solução, que consiste em reformar o espaço e o tempo. O fio de uma racionalidade direta já não parece suficiente, aqui, para guiar sozinho o movimento do pensamento: a dificuldade era de fato um obstáculo real, que demandava, para que se seguisse adiante, um verdadeiro salto conceitual. Einstein nada mais nos disse a esse respeito, e sem dúvida não teria sabido reproduzir exatamente a seqüência de reflexões que acompanhou a tomada de consciência da dificuldade. Não conhecemos senão o momento da saída: o espaço e o tempo, que servem para exprimir os fenômenos físicos e os movimentos dos corpos, deviam ser concebidos como grandezas plenamente físicas, portanto submetidas elas mesmas aos dois princípios, o que deveria conduzir à mudança da sua definição.

Como a reflexão de Einstein passou do enunciado da dificuldade a uma tal solução, que corresponde, de fato, à inversão do problema? Deixando de considerar os dois princípios como irreconciliáveis (a velocidade da luz, enquanto estremecimento do éter, não poderia ser a mesma em todos os referenciais de inércia, o que contrariava o princípio da relatividade), ele os admitiu como fundamentais e reconstruiu sobre eles toda a física. Ou melhor, toda a teoria do movimento enquanto tal, ou seja, toda a cinemática, e as modificações da física propriamente dita (pois não se tratava nesse momento de uma reconstrução, mas de um ajuste) viriam em seguida.

É que os dois princípios irreconciliáveis não estavam sozinhos, mas constituíam um complexo conceitual com as propriedades que os acompanhavam. $\mathrm{O}$ obstáculo que se erguia perante o pensamento pode ser visto como um nó de conceitos imbricados, no qual nada permite à primeira vista a identificação dos fios que possibilitam a resolução do novelo embaraçado. Somente um tipo de apreensão sintética imediata, mais intuitiva do que analítica, deu a ver, de súbito, depois de várias semanas de esforços infrutíferos, uma via de saída, os fios a serem puxados.

Entre as propriedades que sustentavam os dois princípios, uma saltou à vista, proposição implícita que os estreitava. Einstein a indica em suas retrospec- 
tivas: era a regra de adição galileana das velocidades. A partir daí, não havia mais apenas duas, mas três proposições que, tomadas em conjunto, eram irreconciliáveis. Tal foi o fio que permitiu o desfecho: se fosse suprimida a regra das velocidades, os dois princípios poderiam ser conciliados, mediante uma outra regra de composição a ser buscada. Era preciso ter a idéia mencionada acima da inversão de perspectiva teórica, e também pensar no espaço e no tempo como grandezas físicas, contrariamente a suas definições absolutas admitidas por Newton. Eis aí toda uma rede de reflexões, incluindo a crítica dos conceitos físicos (e a influência, entre outras, da análise de Mach), que deve ter tido um papel relevante, por meio de um apelo sintético da intuição. No trabalho teórico sobre essas grandezas, uma vez ultrapassado o obstáculo, o lugar ocupado pela questão da simultaneidade e pela crítica de seu caráter absoluto é revelador da complexidade dessas noções em conjunto, ligando-se além disso à tomada de consciência da impossibilidade de ações instantâneas à distância.

Podemos identificar com bastante precisão o que foi, em Einstein, o momento da invenção de sua solução (solução da dificuldade identificada), que determinou sua descoberta da teoria da relatividade. Esta comporta, a partir da ordenação das relações entre os conceitos físicos, e em primeiro lugar entre os espaços e os tempos, uma parte de dedução (as equações de transformação que fazem a passagem de um referencial de inércia a outro), depois do momento de intuição sintética que abriu o caminho, e a reconstrução das grandezas no percurso desse caminho a partir de então balizado.

Mas onde se situa o ato propriamente criador? Bem se nota que ele caracteriza todo o movimento do pensamento, desde a própria fixação de um alvo para si, pela escolha de suas próprias razões, através de uma formulação dos problemas condicionada por uma certa exigência de inteligibilidade, depois a identificação das dificuldades a superar e, em seguida, a formulação de um princípio de uma solução, até as modalidades do trabalho mais comum (no que ele tem de essencialmente demonstrativo e dedutivo) de estabelecimento das relações de grandezas que são o corpo da teoria. Esse trabalho de criação utiliza o raciocínio (que não encerra apenas dedução, mas é também construtivo ao constituir os objetos) tanto quanto a intuição, termo pelo qual designamos aqui uma percepção (intelectual) sintética de um complexo de conceitos. Acrescentemos ainda que o raciocínio, mais explícito, e a intuição, concebida neste sentido, não são dois modos de pensamento em oposição, já que na escolha de seus caminhos o raciocínio é freqüentemente guiado pela intuição (o que é evidente no caso em estudo).

Pode-se seguir de maneira semelhante a gênese, no pensamento de Einstein, da teoria da relatividade geral como extensão do princípio da relatividade e generalização da teoria da relatividade restrita a quaisquer movimentos. A constituição de tal teoria também comporta diversas fases, que podemos retraçar mais facilmente que no caso anterior. Cada uma delas foi pontuada por publicações 
importantes, e as reflexões e as observações do autor que acompanhavam seu andamento ou dele faziam a retrospectiva, em número bem maior, esclarecem certos aspectos característicos de seu trabalho, em particular as suas intenções programáticas.

Mas tampouco aí isto significaria que uma reconstituição completa seja possível. Se um fio de racionalidade clara corre ao longo do trabalho de elaboração dessa teoria de um novo gênero (uma teoria das invariâncias conducente a uma espécie de geometria da gravitação), ele se perde em diversas retomadas nos nós complexos que somente uma intuição de gênio e a aquisição de uma habilidade no manejo do formalismo matemático poderiam resolver. A criação, talvez aqui mais do que em qualquer outro caso, torna-se manifesta, e Einstein tinha plena consciência desse aspecto.

A consciência desse salto explícito do pensamento criador para edificar, do início até o fim (ou quase isso) uma teoria física que parecia então radicalmente nova foi fundamental para seu pensamento físico e epistemológico. Esta consciência radicalizou a sua concepção da natureza do trabalho teórico e reorientou em parte a sua maneira de abordar os problemas físicos, modificando sua concepção do papel da matemática. Este exprimia a partir de então melhor que tudo, a seu ver, o salto criador necessário à representação teórica da realidade física. "É na matemática que reside o princípio criador" - chegou ele a escrever, a esse propósito (Einstein, 1933). No entanto, esta fase, cujo sentido não nos deve iludir (o trabalho matemático permite realizar uma demanda física) (Paty, 1993: capítulo 5), foi precedida por outras, em que a inteligência criadora se apoiava, mais classicamente, como a anterior, sobre um pensamento dos fenômenos, de seus princípios e conceitos.

$\mathrm{Na}$ origem da teoria da relatividade geral, encontravam-se duas considerações de natureza conceitual, ambas ligadas com uma crítica da inércia, propriedade fundamental dos corpos materiais e de seu movimento. A primeira concernia à natureza dos referenciais de inércia, animados por movimentos retilíneos e uniformes uns em relação aos outros, aos quais apenas se aplicava o princípio de relatividade da primeira teoria (relatividade restrita aos movimentos inerciais). A escolha desse tipo de movimento é arbitrária, observou Einstein, porque nós é que escolhemos os movimentos inerciais dentre todos aqueles que existem na natureza. Reencontra-se aqui a exigência de objetividade para as teorias: com essa diferença frente à anterior (a indução eletromagnética no caso da relatividade restrita), sem o apoio de qualquer evidência dada pelos fenômenos. Para Einstein, ela não deixava de corresponder a uma exigência fundamental, filosófica, sobre a natureza e sua representação. Seguia-se daí a necessidade de estender o princípio de relatividade a quaisquer movimentos, superando o "privilégio" concedido aos movimentos inerciais.

A outra consideração, formulada ao mesmo tempo que a primeira, tratava do conceito de massa inercial, que caracteriza, de fato, tal como a relatividade 
restrita o estabelecia, não somente os corpos, mas também as trocas de energia: apesar de o laço que estabelecia entre a energia e a inércia, a teoria da relatividade restrita se calava acerca da relação entre a inércia e o peso. $O$ efeito desse questionamento foi a formulação do princípio da igualdade da massa inercial e da massa gravitacional (o "princípio de equivalência”).

$\mathrm{Na}$ gênese das idéias de Einstein, esta segunda razão parece ter sido a que mais suscitou a sua reflexão, fazendo com que ele tomasse consciência do caráter imperativo da primeira (todos os fenômenos podiam ser tratados no quadro da relatividade restrita, exceto a gravitação, devido à sua ligação com os movimentos acelerados). Ela se traduzia para ele numa "experiência de pensamento" (Gedenkenexperiment), que ele próprio qualificou mais tarde como "o pensamento mais feliz da [sua] vida", resumido na seguinte frase: "Se alguém cai num movimento de queda livre, ele não sente o próprio peso" (23). Isso equivale a transcrever a igualdade (a identidade) da massa inercial e da massa gravitacional numa equivalência entre um campo de gravidade, ou de gravitação, homogêneo, e um movimento uniformemente acelerado. Einstein assim se dava conta de que não se tratava tanto de incorporar o campo de gravitação à teoria da relatividade (restrita), mas sobretudo de utilizá-lo como meio de ultrapassar a covariância privilegiada dos movimentos inerciais, generalizando-a a todos os tipos de movimentos. Ele esperava que tal generalização lhe "fornecesse de um só golpe a solução do problema da gravitação" (Einstein, 1946). A essência da teoria da relatividade geral se encontrava, portanto, nesse pensamento, e o artigo de 1907 esboçava, em conclusão ao que fora exposto da teoria da relatividade restrita, o programa de sua pesquisa nessa direção.

É possível seguir quase que passo a passo seus esforços para realizar esse projeto até a instauração da teoria da relatividade geral no final do ano de 1915 (24). Mencionemos aqui apenas, ainda que não o possamos detalhar, o primeiro "momento matemático" da invenção, que data de 1912: Einstein percebia então a insuficiência do espaço euclidiano e a necessidade de uma formalização matemática do problema da covariância geral sobre o modo de espaço-tempo (relativista) de Minkowski, estendido com a ajuda do cálculo tensorial absoluto de Ricci e Levi-Civitta (Paty, 1993: capítulo 5). Era-lhe agora necessário "criar pela matemática", chegando às equações que em todos os pontos do espaçotempo apresentavam a métrica não-euclidiana em função do campo de gravitação nesse ponto. 


\section{Indução natural ou criação livre? Papel da intuição}

Pode-se dizer, num certo sentido, que Einstein descobriu, através de suas experiências com as geometrias não-euclidianas para a relatividade geral, aquilo que Poincaré tinha exprimido a propósito das analogias matemáticas e da livre invenção (25): contudo, muito raramente se levou em consideração o laço entre essas duas idéias, em sua natureza fundamental, naquilo que concerne à física. A concepção empirista de uma indução concebida como necessidade lógica a partir dos fenômenos ainda predominava na maioria dos físicos (Pierre Duhem e alguns outros eram raras exceções). Mesmo Poincaré, que criticava o empirismo na matemática bem como o apriorismo, tinha a respeito da física uma atitude menos radical, mais empirista em sua prática assim como em suas concepções (Paty, 1996a; [c]). De todo modo, a distância que ele via entre o domínio da natureza e suas formas teóricas (escolhidas por convenção) lhe permitia apoiar sobre estas todas as possibilidades da invenção matemática. Ele pensava, por exemplo, na eletrodinâmica relativista, em termos de invariantes e de grupos de transformações, e foi além disso o primeiro a praticar esse método (26).

Devemos agora, portanto, retornar às concepções epistemológicas e filosóficas de Poincaré e Einstein, que se relacionam aos elementos destacados na evocação de suas experiências criadoras de formas racionais, de conhecimentos científicos.

\section{A intuição em Poincaré}

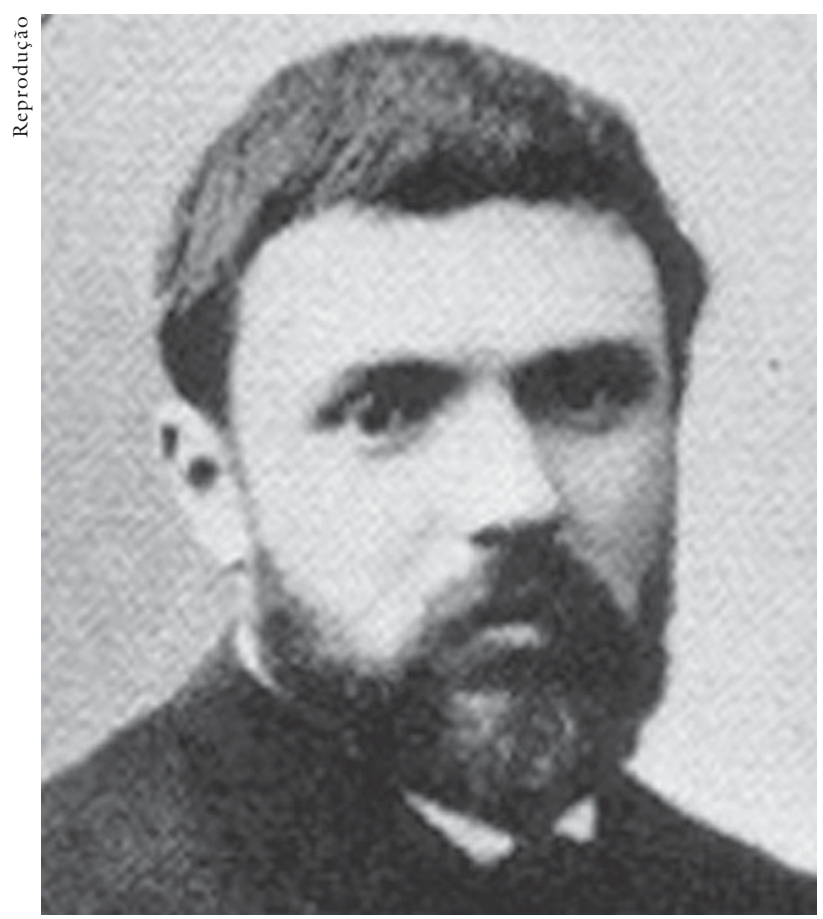

Não retomaremos aqui as análises de Poincaré, a partir da gênese e da natureza da geometria, assim como dos princípios, generalizados e transformados de proposições factuais em enunciados normativos, que ele concluiu com a crítica ao empirismo e ao apriorismo kantiano, bem como com a afirmação do seu convencionalismo (p. ex. Poincaré, 1902). Insistiremos sobretudo na sua concepção da intuição, noção central da sua filosofia do conhecimento.

Henri Poincaré (1854-1912) 
Para ele, a intuição é necessária a todo trabalho criador, em qualquer ciência. Ela se apresenta, certamente, sob formas as mais variadas, que vão desde “o apelo aos sentidos e à imaginação", a indução a partir dos fatos, até por fim a indução matemática ligada à "intuição do número puro" (Poincaré, 1900) - sendo esta última próxima das intuições kantianas a priori. Mas ele acrescenta um complemento indispensável à lógica que, por si só, não basta, nem para o ensino, nem para o trabalho de pesquisa: útil para que o estudante aprenda a amar a matemática, "a intuição (...) o é ainda mais para o cientista criador". Pois é ela que faz "ver o alvo de longe", que permite a "visão de conjunto" sem a qual não existiria invenção (Poincaré, 1900).

Devemos evocar aqui o que Poincaré denomina "analogias matemáticas", que exprimem as relações "verdadeiras", as relações de estrutura, na profundidade dos fatos matemáticos ou físicos; elas justificam e permitem a passagem, por uma extensão criadora, do particular ao geral. No que diz respeito à física, a extensão dos princípios permite atingir plenamente a física teórica e matemática (27). Todo o ofício do matemático ou do físico consiste em saber descobrir "as analogias verdadeiras, profundas, que os olhos não vêem e que a razão adivinha", graças ao "espírito matemático, que desdenha da matéria para se ater apenas à forma pura". A analogia neste sentido é inseparável do movimento do pensamento que escapa à simples comparação e à indução empirista, para "inventar livremente".

Nessa invenção, para Poincaré, é a intuição que detém o papel principal, tanto na matemática quanto na física: "Inventar é discernir, é escolher", e é a intuição de ordem matemática que permite adivinhar as harmonias e as relações ocultas (Poincaré, 1908c, 1918: 47-48). Mas, não é escolher senão num único sentido em particular, pois as combinações estéreis não se fixarão no espírito do matemático criador, que se aterá a construir aquelas que forem úteis, em minoria ínfima com relação a todas as combinações possíveis: diríamos, talvez mais exatamente, que inventar é ver. E ver nos remete à intuição, que deve ser objeto de formação, exercício, para atingir um nível superior às intuições diretamente sensíveis. O grau elevado de desenvolvimento dessa intuição permite a capacidade de inventar e de ser criador.

Poincaré enfatizava, entre os matemáticos, o "espírito de intuição", por oposição ao "espírito de análise". Em larga medida, para ele, a intuição se opunha à lógica, e é sabido que ele se sentia mais próximo da primeira (Poincaré, 1889). A primeira função do ensino de matemática era, a seu ver, desenvolver essa faculdade. Isso porque o geômetra puro deve possuir "a arte de escolher entre todas as combinações possíveis" dos termos propostos à razão, e essa arte é dada pela intuição, não pela lógica: "É através da lógica que se faz demonstrações, mas é através da intuição que se faz invenções”. Sem esta última, acrescenta ele, o geômetra seria como "um escritor que dominaria totalmente a gramática mas não teria idéias”. Mas a intuição também se impõe ao se relacionar o mundo 
matemático com o mundo real, pois só ele pode "transpor o abismo que separa o símbolo da realidade".

Assim, no mesmo texto, de 1889, "A lógica e a intuição na ciência matemática e no ensino”, em que este opõe o espírito de análise e o espírito de intuição - duas tendências daquilo que poderíamos chamar de "estilo" dos matemáticos Poincaré admite que os matemáticos que têm - e louvam - a preferência por espírito de análise e raciocínio lógico também deveriam desenvolver algum tipo de intuição. É que, para ele, mesmo na Análise pura, se "só a lógica (...) pode dar a certeza [e] é o instrumento da demonstração", é ainda "a intuição [que] é o instrumento da invenção".

Essa "intuição pura", dirigida para as formas, relaciona-se à "intuição do número puro", por oposição a uma intuição mais sensível. É ela que permite que o analista sinta o "princípio de unidade interna" das entidades abstratas nas quais se baseia o pensamento, segundo a função de percepção sintética atribuída de maneira geral à intuição. Citando o exemplo do matemático Charles Hermite, notório analista, Poincaré relembra a metáfora com a qual este caracterizava esse gênero de intuição que trabalha com base em entidades formais: "As entidades mais abstratas eram para ele como seres vivos”. É a apreensão imediata do seu princípio de unidade (o "não sei que princípio de unidade interna" sentido pelo criador, sem projeção numa imagem sensível), que lhe permite compreendê-las e lhe faculta a capacidade de invenção: ela tem, neste sentido, o mesmo papel que a intuição mais sensível. Sendo assim, Poincaré mantém a diferença entre a "intuição pura" dos analistas e a intuição sensível: elas "não têm o mesmo objeto" e remetem a "duas diferentes faculdades de nossa alma", que são como "dois projetores voltados para dois mundos estranhos um para o outro", e correspondem a duas modalidades distintas da invenção.

O próprio Poincaré se situava próximo à segunda, a faculdade de "intuição sensível" que a seu ver era, apesar de tudo, "o instrumento mais comum da invenção" na matemática (Poincaré, 1889). Os matemáticos de "espírito intuitivo" neste sentido se apoiam geralmente, em seu trabalho de análise, em imagens não somente geométricas, mas também físicas. Estas podem estimular a intuição (sensível) matemática, ajudando-a a encontrar a solução antes de ter os meios da demonstração, e a "ver de um só golpe o que a dedução pura não lhes mostraria senão sucessivamente". As "analogias físicas" permitem pressentir as verdades matemáticas que escapam ainda ao rigor do raciocínio, como, por exemplo, ocorreu a Félix Klein ao usar as propriedades das correntes elétricas para resolver certa questão relativa às superfícies de Riemann (Poincaré, 1889). O rigor no sentido do analista viria mais tarde: pelo menos o resultado é obtido, e disto não se duvida, embora ainda sem a obtenção da certeza matemática. É desta maneira "que são feitas quase todas as descobertas importantes". 


\section{Einstein e a liberdade lógica}

Einstein tinha encontrado na epistemologia de Ernst Mach a idéia do caráter relativo e provisório dos conceitos e das teorias; na filosofia de David Hume, a crítica da indução - liberando a relação entre os fenômenos e os conceitos; e na de Immanuel Kant, a idéia de que a realidade do mundo exterior, posta "diante de nós como um enigma", nos é inteligível, havendo a necessidade, para pensar, de conceitos e categorias independentes da experiência (Einstein, 1936).

Elaborando sua própria concepção da relação entre as representações teóricas e os dados da experiência e as impressões dos sentidos, ele encontrou também nos escritos de Henri Poincaré elementos de reflexão que lhe permitiram escapar dos limites do apriorismo kantiano ultrapassando também aquilo que faltava à crítica de Hume: notadamente a idéia do livre arbítrio no raciocínio. Mas quando Poincaré fazia desta consideração a pedra angular do seu convencionalismo, Einstein a integrava a uma perspectiva racionalista, ao preço de uma transformação da solução kantiana. Ele estimava poder-se "dizer mais ainda" do que Kant: "que os conceitos que aparecem em nossos pensamentos e em nossas expressões lingüísticas são - considerados de um ponto de vista lógico - criações livres do pensamento", conceitos esses que "não podem ser obtidos pela indução a partir da experiência dos sentidos" (Einstein, 1944). Porque "um abismo (intransponível logicamente)" se abre entre "o mundo da experiência sensória [e] o dos conceitos e das proposições", que são na verdade invenções livres (28). Não temos espontaneamente a consciência disto, devido ao hábito adquirido de associá-los entre si. É essa "liberdade lógica" que permite construir conceitos e representações teóricas, segundo a escolha das regras que parecerem mais adequadas.

Essa idéia está no cerne das epistemologias de Poincaré e Einstein, de suas respectivas concepções da relação entre o pensamento racional e o mundo real, e de seu pensamento sobre a criação científica.

\section{Os processos criativos do pensamento racional}

\section{Poincaré}

Para Poincaré, em grande parte, o trabalho científico consiste em selecionar entre os fatos, que se oferecem multitudinários, aqueles que são os mais ricos de significação - isto somente porque "o cérebro do cientista, que não passa de um ponto no universo, jamais poderá conter o universo inteiro”. Eis aí o físico ou o matemático que, incapaz de simplesmente reproduzir - o que, além do mais, seria sem dúvida insuficiente para compreender - encara a necessidade de inventar. Ater-se a relações de semelhança superficial entre os fatos não produziria nada senão banalidade e repetição, sem que se encontrasse o acesso às relações significativas. 
As similitudes portadoras de sentido (que são as "analogias matemáticas", para Poincaré) transcendem as diferenças materiais; quanto mais distantes forem os fatos cuja relação se verifica fecunda, mais essencial será a propriedade que eles revelam - o que também corresponde a um caráter estético (29). A fecundidade da relação entre os fatos, matemáticos ou físicos, é marcada pelo fato de eles fazerem aparecer uma ordem entre os elementos que antes pareciam não-relacionados, ou abandonados ao acaso, e por conduzirem ao conhecimento de uma lei. A formação de tais combinações fecundas advém do processo de "invenção matemática"; é atingir aquilo que Poincaré com freqüência remete à "harmonia", referindo-se à "beleza intelectual" e à "elegância matemática” (Poincaré, 1908a in 1918: 15-17).

O que Poincaré chama de harmonia, corresponde à instantaneidade da evidência para o espírito, que é atingida, no final das contas, através da inteligibilidade - para ele assim como para Descartes (30), dois séculos e meio antes. "Quanto mais vermos esse conjunto claramente e de um só golpe", escreveu ele, "melhor perceberemos suas analogias com outros objetos vizinhos, e em conseqüência mais chances teremos de descobrir as generalizações possíveis" (Poincaré, 1908b in 1918: 26). E um raciocínio "meio intuitivo" permite ver simultaneamente, em razão de sua brevidade, suas diversas partes, "de modo que se percebe imediatamente aquilo que deve ser modificado para que se adapte a todos os problemas de natureza semelhante que possam vir a se apresentar" (Poincaré, 1908b in 1918: 26).

Convém especificar que a invocação da analogia, freqüente em Poincaré, concerne essencialmente ao resultado final. A analogia é apenas a lição que se tira, quando as relações vêm à tona e sua fecundidade se manifesta. É sempre a "analogia matemática" que está aí em jogo, indicando a estrutura e a unidade profundas dos elementos relacionados na descoberta. No trabalho criativo, em que opera a faculdade da intuição - essa intuição que permite "enxergar o alvo de longe", que oferece a "visão de conjunto" sem a qual não haveria invenção (Poincaré, 1897) -, as propriedades a serem consideradas se apresentam ao entendimento sob sua forma própria, sobre a qual o raciocínio trabalha diretamente.

Nesse processo é ao inconsciente, com efeito, que Poincaré atribui a tarefa de estabelecer as combinações de idéias úteis, por eliminação e escolha. O trabalho preparatório de fixar a atenção num determinado problema deslancha a atividade inconsciente, em que o pensamento consciente define e indica "mais ou menos" a direção geral. Para representar essa atividade inconsciente, que opera sobre as idéias elementares a serem combinadas entre si, ele recorria à metáfora sobre os "átomos retorcidos de Epicuro", arremessados em todos os sentidos e combinando-se entre si à nossa revelia, sendo que apenas a combinação retida se ofereceria depois ao pensamento consciente.

Para Poincaré, o inconsciente "sabe escolher, sabe descobrir". Ele se perguntava inclusive se o "eu subliminar [não seria] superior ao eu consciente", 
numa hipótese antes examinada pelo filósofo Émile Boutroux (31). Jacques Hadamard, por sua vez, iria contestar o sentido dessa expressão, preferindo a idéia de uma cooperação entre os dois (Hadamard, 1945). Poincaré se inclinava a considerar que o "eu subliminar" privilegia os fenômenos que afetam a sensibilidade na direção da harmonia, da beleza matemática, essa sensibilidade estética correspondente na matemática às soluções oriundas da lei que se está procurando (Poincaré, 1908c: 53-59). Mas o problema de saber mais exatamente o que encobrem os termos que remetem às considerações estéticas permanece em aberto, exceto por tratar-se - nas ciências como nas artes - de formar ou exprimir significações fortes.

\section{Einstein}

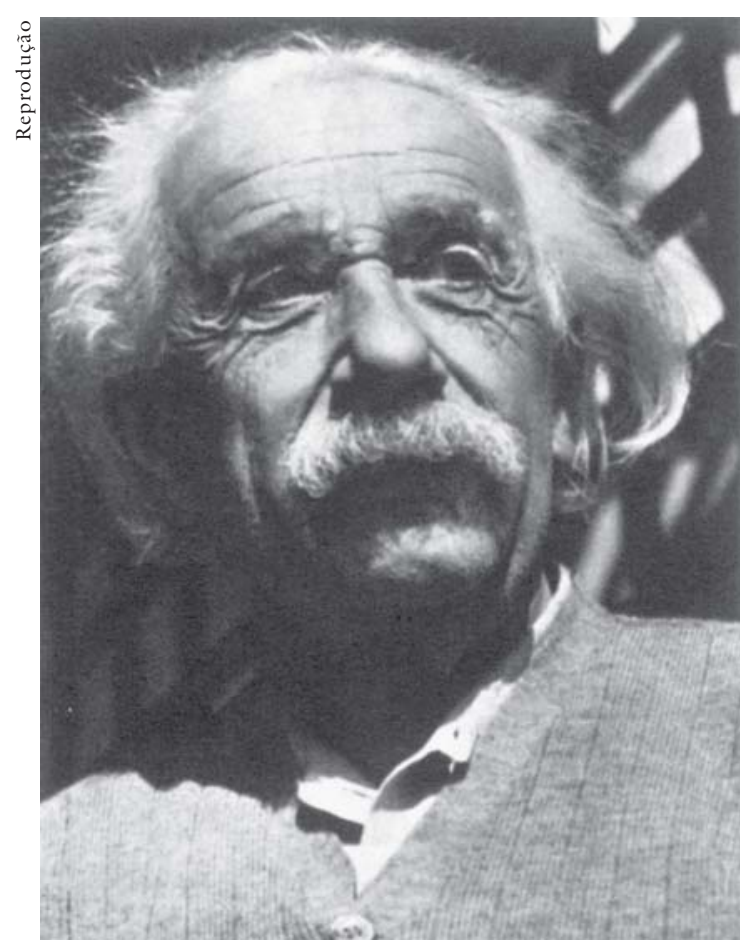

Einstein concebia a experiência da criação científica como uma forma particular da experiência mais geral do pensamento. Segundo ele, o ato de "pensar" põe em jogo, além das imagens resultantes das impressões dos sentidos, os conceitos, "todo o nosso pensamento [sendo] um jogo livre com os conceitos" (Einstein, 1946: 6-7). Entretanto, embora o pensamento de um indivíduo se forme graças ao aprendizado e ao uso social das palavras (Einstein, 1941), ele julgava, por experiência própria, que o pensamento conceitual "se desenrola em larga medida sem fazer uso de signos (palavras)". E também considerava, em consonância com o que dizia Poincaré sobre a invenção científica, que ele se efetua "de fato, num grau elevado, de maneira inconsciente" (Einstein, 1946: 6-7).

Além disso, ele ligava o pensamento científico, seja em se tratando de sua formação no indivíduo ou da criação, à experiência do espanto, tal como ele relata ter experimentado na infância, aos quatro ou cinco anos de idade, ao ver girar a agulha de uma bússola; ou ainda, mais tarde, ao descobrir num livro as demonstrações da geometria de Euclides (Eistein, 1946: 8-11). O filósofo Baruch de Espinosa, cerca de três séculos antes, tivera uma experiência semelhante de iluminação de sua inteligência a propósito da média proporcional (32).

A experiência do conhecimento, para Einstein, era ao mesmo tempo a da aquisição da intuição (33): a intuição física para aquilo que lhe dizia respeito, que 
constituía o que ele ainda denominava seu "instinto científico", que freqüentemente evocava a propósito do sentido de tal conceito, assim como a propósito dos debates sobre a direção que deveria tomar, a seus olhos, a teoria física. Essa intuição, à qual ele requeria, desde seus anos de estudante, que "distinguisse claramente o que é importante do ponto de vista fundamental, por meio do que se pode assegurar as bases, daquele resto de erudição mais ou menos supérflua”, opera na racionalidade, no estágio da invenção como no da avaliação e no da crítica - por exemplo, sobre a física quântica (Paty, 1994 [c]). Em todo caso, antes da análise vem o estágio da invenção propriamente dita, na qual a intuição desempenha o papel principal.

Trabalhar com as idéias é sempre, para Einstein, trabalhar com a racionalidade. Não se pode, no entanto, fazer da intuição, e da invenção na qual desempenha um papel tão grande, uma descrição normativa: ela advém da experiência singular, e se liga à atividade mental em geral. É uma visão imediata, a partir da qual se pode reconstituir logicamente as razões, mas que repousa sobre as experiências anteriores do pensamento, e os processos mentais relativos à atenção a um problema seguem geralmente um caminho indireto (34). Sua experiência, acima evocada, mostra que o importante, neste sentido, é estar impregnado da consideração do problema, tê-lo volvido e revolvido até chegar a uma formulação racional que porte em si a virtualidade da solução.

Pois o pensamento é guiado por uma certa maneira de dispor seus elementos de informação: chegar à solução de um problema é formar uma imagem clara ao final do processo, escolhendo entre os elementos deixando-se guiar pela intuição. Vale o mesmo para os conceitos, que fazem o pensamento, e a partir dos quais se forma uma representação inteligível do mundo, e para as palavras da linguagem: tais signos são ligados às impressões sensíveis por certas regras, segundo uma correspondência relativamente estável (Einstein, 1936; 1941). Na ciência, o sistema de conceitos que visa a uma representação das experiências dos sentidos é, "no que concerne à lógica", "um jogo livre com os símbolos segundo as regras do jogo dadas arbitrariamente (quanto à lógica)". O mesmo se pode dizer também sobre o "pensamento de todos os dias" (35).

A experiência do pensamento dos conceitos, em particular do pensamento científico, faz intervir um pensamento ao mesmo tempo consciente e semiconsciente, para o qual o conceito funciona como um signo particular, sem se identificar a uma palavra. "Não é necessário", indica Einstein (1946), "que um conceito seja relacionado a um signo (uma palavra) perceptível pelos sentidos e reprodutível; mas quando é o caso, o pensamento se torna comunicável". Para ele, o "pensamento se desenrola em larga medida sem fazer uso de signos (palavras), de fato, num grau elevado, de maneira inconsciente".

Analisando seu próprio caso, ele assinalou, ao responder ao questionário de Jacques Hadamard sobre "a psicologia da invenção no domínio matemático" 
(Hadamard, 1945), que "as palavras e a linguagem, escritas ou faladas, não parecem desempenhar o menor papel no mecanismo do meu pensamento" (Einstein, 1945). Sobre o funcionamento deste, ele ofereceu então as seguintes informações: "As entidades psíquicas que servem de elementos ao pensamento são certos signos ou imagens mais ou menos claras, que podem ser reproduzidas e combinadas 'à vontade'", e que estão em relação com conceitos lógicos do problema posto. A atividade mental, o "jogo bastante vago" sobre esses elementos ou signos (que, no caso, são “de tipo visual e às vezes motor”), é sustentada emocionalmente pelo "desejo de enfim atingir os conceitos logicamente relacionados", e o jogo sobre os elementos em questão "visa ser análogo a certas conexões lógicas que estamos pesquisando". Somente num estágio secundário, quando as associações encontradas entre os elementos são bastante estáveis e podem ser reproduzidas à vontade, partimos "a custo" em busca "de palavras ou outros signos convencionais” que possam exprimir a solução nos termos do problema (Einstein, 1945).

O lingüista Roman Jakobson assinalou a concordância entre a descrição feita por Einstein do gênero dos signos que entram no processo de pensamento e aquela que ele mesmo poderia propor, a saber, que "os signos são um apoio necessário do pensamento", e que "o pensamento interior, sobretudo quando é criador, prefere [à linguagem comum] os sistemas de signos que são mais flexíveis, menos padronizados do que a linguagem e que dão mais liberdade e dinamismo ao pensamento criador" (Jacobson, 1980).

\section{Conclusões}

O tema da criação científica, tal como o encontramos na experiência vivida de cientistas que também foram filósofos, como Poincaré e Einstein, parece ligado, de um lado, a processos de pensamento em que a racionalidade, mesmo se não for total, permanece essencial e passível de ser apreendida em diversas seqüências, entre uma problematização inicial e a obtenção de resultados; de outro lado, a problemas epistemológicos fundamentais sobre a constituição e a natureza do conhecimento científico. É assim natural que esse tema pertença de direito ao domínio da investigação filosófica e que não possamos nos contentar em remetê-lo à psicologia ou ao estabelecimento de consensos sociais cristalizados em "paradigmas".

Sobre o primeiro aspecto, mesmo nos momentos em que o fio de um raciocínio não se deixa ver, e quando ele se perde nos nós complexos que o pensamento parece vencer a saltos, tudo indica que a atividade inconsciente do espírito é dirigida por uma atenção, um esforço, uma vontade. Poincaré atribuía ao inconsciente a tarefa de estabelecer as combinações de idéias que são úteis, por eliminação e por escolha (Poincaré, 1908c in 1918).

Retomando a comparação feita por Poincaré entre as idéias elementares e os átomos entregues ao acaso, Hadamard imaginou o espírito, em sua primeira 
reflexão sobre um problema, discutindo os elementos de idéias, e estes últimos, no período inconsciente, continuando seu percurso de maneira desordenada: "Essa desordem pode ter grande valor, porque os raros confrontos que são úteis, sendo de natureza excepcional e produzindo-se entre idéias que são muito afastadas, serão provavelmente os mais importantes" (36). É uma imagem que se aproxima da idéia de parentescos profundos, mas não aparentes, entre elementos conceituais distanciados, que recobrem as analogias matemáticas no sentido desenvolvido por Poincaré. Elas serão aqui apreendidas em seu próprio movimento.

A elegância matemática é a forma daquilo que dá, nos termos de Poincaré, a "harmonia" e a "beleza intelectual" (37), que correspondem à instantaneidade da evidência, à qual, afinal, para Poincaré e para Einstein, assim como para Descartes três séculos atrás (Paty, [a]), se liga a inteligibilidade.

Os psicólogos Paul Souriau e F. Paulhan, que se interessaram pela invenção - citados por Hadamard -, defendiam a esse respeito pontos de vista contrários: Souriau (1881) considerava que ela se produzia por acaso, enquanto Paulhan (1904) nela via, mais classicamente, o efeito da reflexão. Para Hadamard (1945), a atividade mental inconsciente, a seu ver essencial para o processo, não se efetua de modo algum por acaso: "A descoberta", escreveu ele, "depende necessariamente da ação preliminar mais ou menos intensa do consciente", assinalando o que Poincaré tinha dito sobre a ação diretora da consciência sobre o inconsciente, definindo "mais ou menos a direção geral na qual o inconsciente deve trabalhar".

Essa diretividade do consciente sobre o inconsciente é traçada por outros filósofos nos termos mais precisos de um tipo de esquema geral dos processos do pensamento. Théodore Ribot propunha uma espécie de algebrização dos signos mentais em função do problema considerado em seus termos racionais: resolve-se um problema supondo-o já resolvido, e busca-se qual é a combinação de elementos que permite a solução: chega-se primeiro ao resultado, depois volta-se atrás para estabelecer o fio que a ele conduziu (Ribot, 1900). Retomando essa idéia em sua reflexão sobre o "esforço intelectual" (Bergson 1919, in 1959: 947) acrescentou que "o todo se apresenta como um esquema", e "a invenção consiste precisamente em converter o esquema em imagem", e a imagem contém "os meios pelos quais o efeito foi atingido" (Bergson, 1919 in 1959: 958) Transcrevendo nesses conceitos a observação do psicólogo Paulhan (1901) de que a invenção literária e poética vai "do abstrato ao concreto", Bergson escreveu que a invenção, artística ou científica, vai “do todo às partes e do esquema à imagem”.

Para Bergson, o esforço mental supõe "elementos intelectuais em vias de organização", com uma tendência ao "monoideísmo", que é um estado característico da atenção: a unidade (mas não a simplicidade) assim traçada é a de uma “idéia diretriz comum a um grande número de elementos organizados". Ele acrescenta: "é a própria unidade da vida". Esse esforço intelectual sobre as imagens que não têm em entre si senão "semelhança interior", como uma "identidade de 
significação" (Bergson, 1919 in 1959: 958), lembra as analogias matemáticas de Poincaré.

Num sentido bem parecido, Meyerson se interrogava sobre os esquemas que a razão segue ao constituir as imagens da realidade, tais como, por exemplo, as da física, ou pelo menos sobre as "tendências a que o espírito do pesquisador obedece", e que "a razão procura fazer com que prevaleçam..." (38). Ele relacionava sua enquete à insuficiência das concepções apriorística e empirista no que concerne à aquisição das ciências, em particular da matemática, e ao conhecimento dos "verdadeiros domínios da reflexão matemática". Se ele os via, por sua vez, num movimento do diverso em direção ao idêntico, isso não representa uma reconstituição ou uma redução às formas da racionalidade que nos parecem familiares com a ciência atual, e seu propósito de interrogar as formas históricas do conhecimento era similar, para ele, ao dos antropólogos que se preocupam em compreender a lógica própria da "mentalidade primitiva" - como os esquemas de participação de Lévy-Bruhl (Meyerson, 1931 v. 1: 81). Sob a diversidade das formas de raciocínio ele descobria um esquema comum a qualquer pensamento humano. Seja qual for a teoria envolvida, o problema assim abordado fica posto.

As descrições dos filósofos mencionados - e singularmente as de Bergson tendem então igualmente a mostrar a importância epistemológica dos processos do pensamento criador. Afinal de contas, é por meio de tais criações que os objetos do pensamento são postos, como representações do mundo, por mais provisórias que sejam, e é também por isso que a ciência existe. Parece claro, deste modo, que não basta analisar as formas sob as quais ela é comunicada e ratificada, mas que também importa saber como os elementos do conhecimento surgem com a novidade daquilo que, até então inexistente, é, num certo momento, inventado e criado.

\section{Notas}

1 Descartes, 1637a. A partir, contudo, do esboço, muito avançado mas igualmente abandonado, do Mundo ou Tratado da luz (Descartes, 1633).

2 Descartes, Cartas ao Padre Marin Mersenne, 27 de maio de 1638 e 23 de agosto de 1638, in Descartes, 1964-1974 (AT), v. 2, p. 134-137; 307-320.

3 Ver a apresentação que o próprio Descartes fez no Discurso do método (Descartes, 1637a).

4 Veja-se, p. ex., o "Sistema figurado dos conhecimentos" que acompanha a publicação do primeiro volume da Encyclopédie de d'Alembert \& Diderot (1751-1780), com o Discurso preliminar de d'Alembert (1751).

5 Ver, p. ex., Diderot, 1753. Cf. Paty, 1977, capítulo 4, p. 175-179.

6 Théodore Ribot, pioneiro da psicologia científica, diretor da Revue Philosophique, au- 
tor de um Ensaio sobre a imaginação criadora (Ribot, 1900), professava pontos de vista bastante próximos dos de Poincaré. Nós o reencontraremos nas nossas conclusões.

7 Em seu texto "Sobre o pragmatismo de William James". In: Bergson (1934), 1959, p. 1447.

8 Ver seu texto sobre "O esforço intelectual”, em Bergson (1919), 1959, p. 930-959.

9 Rey, 1911, p. 78. Abrindo caminho a partir daí para a invenção; ver também, p. ex., Le Roy, 1905.

10 Ver, mas tardiamente, Lalande, 1948.

11 Ver em especial Reichenbach, 1938, mas também Popper, 1935; 1972. Sobre esse ponto, ver Paty, 1993 [a], capítulo 1.

12 Aqui entendida no sentido privativo, como se diz "agnóstico". Ver o anarquismo epistemológico de Paul Feyerabend (1975), ou as reduções sociológicas em voga a partir de Thomas Kuhn (1970).

13 Essas formulações foram obra de William Thomson (Lorde Kelvin), Rudolf Clausius, Ludwig Boltzmann, Willard J, Gibbs... Pierre Duhem (1905) enfatiza esse caráter abstrato, que ele via desde então como característico das teorias físicas.

14 As obras mais recentes que levam em conta o papel da imaginação na pesquisa científica ressaltam o seu aspecto psicológico, mas deixam à sombra a sua função para a racionalidade, a não ser para remeter a uma dimensão "estética" que permanece vaga: ver em particular Holton (1978) e Miller (1984).

15 Poincaré (1908c), in 1908a, ed. 1918, p. 43-63, em particular p. 50-63; ver Hadamard, 1945 , p. 22-23.

16 Sobre os trabalhos de Poincaré correspondentes, ver Poincaré, 1880a; 1880b; 19161965 , v. 2; 1997, assim como a sua correspondência com L. Fuchs (Poincaré, 19161965, v. 11).

17 Ver, em especial, Hadamard, 1945, e Jakobson in Hadamard, 1945, p. 93.

18 Os textos fundadores dessas teorias foram republicados na edição crítica das obras completas de Einstein atualmente disponível: Einstein, 1987-1998, v. 2, 3, 7. Para uma tradução francesa dos textos principais, ver Einstein, 1989-1993, v. 2, 3. Consulte-se ainda a correspondência, distribuída em vários volumes dessas edições.

19 Einstein, 1946, p. 32. "Ela devia seu caráter revolucionário", comenta Einstein, ao fato de fazer a passagem da idéia de ação à distância à de campo.

20 Einstein, 1987-1998, v. 1; Einstein \& Besso, 1979. Cf. Paty, 1993 [a], cap. 2.

21 Em particular o manuscrito Einstein, 1920. Para uma análise correspondente, ver Paty, 1993 [a], capítulos 2 e 3. 
22 Sobre o que está epistemologicamente subjacente à formulação de uma "dificuldade" (e não, por exemplo, uma “anomalia”), ver Paty, 1993 [a]; 1996b.

23 Einstein, 1922, 1946. Esse pensamento the ocorreu em novembro de 1907, segundo Abraham Pais, 1982, p. 178).

24 Ver Pais, 1981, e a coleção Einstein Studies, organizada por Don Howard e John Stachel (em particular Howard \& Stachel, 1989 e Eisenstaedt \& Kox, 1992).

25 Ver adiante.

26 Paty, 1996a. Sobre o empirismo de Poincaré na física, cf. Paty, [c]. Sobre os diversos significados da física matemática para Poincaré, cf. Paty, 1999.

27 Poincaré (1897), in 1991, p. 22-28. Sobre o significado da analogia matemática em Poincaré, cf. Paty [b]. Sobre a "física matemática" no sentido dado por Poincaré, cf. Paty, 1999. Sobre o caso da eletrodinâmica e sua transformação por Poincaré numa teoria da "física matemática", cf. Paty, 1996a.

28 Einstein, 1944. Ver Paty, 1993 [a], capítulo 9.

29 Poincaré, 1908a, Livro 1, capítulo 1, “A escolha dos fatos”, ed. 1918, p. 11.

30 Descartes, 1628. Cf. Paty, 1997.

31 Boutroux, citado por Hadamard, 1945. Emile Boutroux era cunhado de Poincaré e amigo de William James.

32 Ver o seu Breve tratado (Espinosa, 1656). Cf. Paty, 1986, p. 294.

33 Em alemão, Einfuhlung. Einstein, 1946c, p. 14-15.

34 Ver, para indicações detalhadas, Paty, 1993, p. 383.

35 Einstein, 1944. Ver a observação antes feita, no mesmo sentido, por Helmholtz, 1971, em texto de 1894 sobre "A origem e a interpretação correta das impressões dos nossos sentidos": "As imagens memorizadas das impressões dos sentidos podem tornarse elementos na combinação de idéias, embora tais impressões não possam ser descritas pelas palavras, e portanto conceitualizadas".

36 Hadamard, 1945, ed. francesa, p. 52-53.

37 Le choix des faits, in Poincaré (1908a), ed. 1918, p. 15-17.

38 Meyerson, 1931, v. 1, p. xix. Ver Meyerson, 1921.

Referências bibliográficas

ALEMBERT, Jean le Rond d'. Discours préliminaire. In: d'Alembert, \& Diderot, Encyclopedie, v. 1, 1751. Reed. Paris, Gonthier, 1965. 
ALEMBERT, Jean le Rond d' \& DIDEROT, Denis (dirs.). Encyclopédie ou Dictionnaire raisonné des sciences, des arts et des métiers, $17 \mathrm{v}+11 \mathrm{v}$. de pranchas. Paris, Briasson, David, Le Breton et Durant, 1751-1780.

AMPÈRE, André-Marie. Essai sur la philosophie des sciences ou Exposition analytique d'une classification naturelle de toutes les connaissances humaines. Paris, Bachelier, 1834. Reimpr., Bruxelas, Culture et Civilisation, 1966.

BERGSON, Henri. L'énergie spirituelle. Paris, Alcan, 1919.

$1249-1482$. La pensée et le mouvant. Paris, Alcan, 1934. In: Bergson, 1959, p.

Oeuvres. Edição do centenário. André Robinet (ed.), Paris, Presses Universitaires de France, 1959; 1963.

BOUTROUX, Émile. De la contingence des lois de la nature. Paris, 1874. Tese (doutorado). Paris, Alcan, 6. ed., 1908.

BOUTY, Edmond. La vérité scientifique. Sa poursuite. Paris, Flammarion, 1908; 1920.

COMTE, Auguste. Cours de philosophie positive, 6 v. Paris, 1830-1842.

DESCARTES, René. Regulae ad directionem ingenii (1628). In: Descartes (19641974, AT), cit., v. 10, p. 349-4 86. Trad. francesa por J. Sirven, Règles pour la direction de l'esprit. Paris, Vrin, 1970.

AT), cit. v. 11, p. 1-118.

Le Monde ou Traité de la lumière (1633). In: Descartes (1964-1974, v. 6, p. 1-78.

Discours de la méthode (1637a). In: Descartes (1964-1974, AT), cit., La Géométrie (1637b). In: Descartes (1964-1974, AT), cit., v. 6, p. $367-486$.

Oeuvres de Descartes (1896-1913); nova edição revista, 1964-1974; reed., 1996 (edição indicada AT).

DIDEROT, Denis. Sur l'interprétation de la natur. Paris, 1753; ed. revista, 1754. In: Pierre Vernière (ed.), Diderot, Oeuvres philosophiques. Paris, Garnier, 1964.

DUHEM, Pierre. La théorie physique, son objet, sa structure, Paris, 1905.

EINSTEIN, Albert. Grundgedanken und Methoden der Relativitätstheorie in ihrer Entwicklung dargestellt (1920), manuscrito inédito. New York, Biblioteca Pierpont Morgan, cópia nos Arquivos Einstein. Trad. ingl. inédita por John Stachel, Fundamental ideas and methods of the theory of relativity presented in their evolution, gentilmente cedida pelo tradutor.

How I created the theory of relativity. Conferência pronunciada em alemão na Universidade de Kioto, em 14 de dezembro de 1922. Texto em inglês a partir da transcrição japonesa in: Jun Ishiwara, Einstein kyozyu kôen-roko (The record of professor Einstein's lectures). Tóquio, 1923; reimpr., Tóquio 1971); trad. por Yoshimasa Ono, Physics to day, agosto de 1982; reprod. in Weart, Spencer \& Philipps, Melba 
(orgs.), History of physics, Readings from Physics to day, n. 2, American Institute of Physics, Nova York, 1985, p. 243-245.

On the method of theoretical physics, The Herbert Spencer lecture, Oxford, 10 de junho de 1933; reimpr. in Einstein, 1954, p. 265-270. Original alemão, Zur Methodik der theorischen Physik, in Einstein, 1934, ed. 1960, p. 113-119. Trad. fr., Sur la méthodologie de la physique théorique, in Einstein, 1989-1993, v. 5, p. 102106.

Mein Weltbild, Querido, Amsterdam, 1934. Reedição (modificada e com textos mais recentes acrescentados), Herausgeben von Carl Seelig. Zurique, Europa-Verlages, 1953; Berlim Ocidental, Ullstein Bücher, 1960.

. Physik und Realität. Franklin Institute Journal, 221, p. 313-347, 1936.

Trad. ingl., Physics and reality. Franklin Institute Journal, 221, p. 349-382, 1933.

Trad. fr., Physique et réalité, in Einstein, 1989-1993, v. 5, p. 125-151.

. The common language of science. Gravação radiofônica de confe-

rência científica. Londres, 28 de setembro de 1941. Advancement of science, Londres, v. 2, n.5, 1941. Trad. fr., Le langage commun de la science, in Einstein, 1989-1993, v. 5, p. $169-170$.

Bemerkungen zu Bertrand Russells Erkenntnistheorie, in Schilpp, Paul Arthur (ed.), The philosophy of Bertrand Russell, Northwestern University Press, Evanston (Ill.), 1944. Trad. fr., Remarques sur la théorie de la connaissance de Bertrand Russell, in Einstein, 1989-1993, v. 5, p. 107-111.

"Testimonial", in Jacques Hadamard. An essay on the psychology of invention in the mathematical field. Princeton, Princeton University Press, 1945; republicado sob o título: A mathematician's mind, in Einstein, 1954, p. 35-36. Trad. fr. Lettre à Jacques Hadamard, in Hadamard, 1945, ed. fr., p. 82-83.

Autobiographisches. Autobiographical notes (1946), in Schilpp, P.A. (ed), Albert Einstein, philosopher and scientist, The library of living philosophers. La Salle (Ill.), Open Court, 1949, p. 1-95. Trad. fr., Eléments autobiographiques, in Einstein, 1989-1993, v. 5, p. 19-54.

Ideas and opinions. Trad. Sonja Bergmann. New York, Crown, 1954. R6-6d., New York, Laurel, 1981 (edição utilizada).

The collected papers of Albert Einstein. Edição de John Stachel, Martin Klein et al., New Jersey, Princeton University Press, 1987-1998, 8 v. publicados.

Oeuvres choisies. Trad. fr. pela equipe de trad. de FENS, Fontenay-StCloud et al. Paris, edição publicada sob a dir. de Françoise Balibar. Seuil, ed. do CNRS, 6 v., 1989-1993.

EINSTEIN, Albert \& BESSO, Michele. Correspondance 1903-1955, publicada por Pierre Speziali, Hermann, Paris, 1972, Textos originais e tradução francesa. Nova ed., somente com a trad. fr., 1979.

EISENSTAEDT, Jean \& KOX, A.J. (eds.). Studies in the history of general Relativity. Boston, Birkhduser, Einstein Studies Series, 3, 1992. 
FEYERABEND, Paul. Against Method (1975). Trad. fr. Baudouin Jurdant e Agnès Schlumberger, Contre la méthode, esquisse dune théorie anarchiste de la connaissance. Paris, Seuil, 1979.

HADAMARD, Jacques. An essay on the psychology of invention in the mathematical field, Princeton University Press, Princeton (ICJ.), 1945. Trad. fr. Jaqueline Hadamard, Essai sur la psychologie de l'invention dans le domaine mathématique. Paris, Gauthier-Villars, 1975.

HELMHOLTZ, Hermann von. Wissenschaftliche Abhandlungen, 3 v. Leipzig, 18821895.

Schriften zur Erkenntnistheorie, herausgegeben and erlaütert von Paul Hertz and Moritz Schlick. Berlim, Springer, 1921.

Selected writings. Russell Kahl (ed.). Middletown (Conn.), 1971.

Epistemological writings. Paul Hertz e Moritz Schlick (eds.). Edição

do centenário, com notas e comentários pelos organizadores. Nova trad. de Malcolm

F. Lowe, com Introdução e bibliografia por R.S. Cohen and Y. Elkana, Reidel.

Dordrecht/Boston, 1978. Trad. e edição em inglês por Helmholtz, 1921.

HOLTON, Gerald. The scientific imagination. Case studies. Cambridge, Cambridge University Press, 1978.

HOLTON, Gerald \& ELKANA, Yehuda (eds.). Albert Einstein, historical and cultural perspectives: the centennial symposium in Jerusalem. Princeton, Princeton University Press, 1982.

HOWARD, Don \& STACHEL, John (eds.). Einstein and the history of general Relativity, Einstein Studies Series, 1, Boston, Birkhduser, 1989.

JAKOBSON, Roman. Einstein and the science of language, 1980. In Holton, Elkana, 1982, p. 139-150. Trad. fr. por Catherine Malamoud: Einstein et la science du langage, Le débat, 20, p. 131-142, maio de 1980.

JAMES, William. Pragmatism: a new name for old ways of thinking, 1907. Trad. fr. E. Le Brun e M. Paris. Prefácio de Henri Bergson, Le pragmatisme. Paris, Flammarion, 1911.

A Pluralist Universe. Londres, 1909; trad. fr. E. Le Brun e M. Paris, Philosophie de l'expérience. Paris, Flammarion, 1910.

Essays in Radical Empiricism, 1912.

JAMES, William. Selected papers on Philosophy, 1917. Lodres, Dent \& Sons, 1956.

KANT, Immanuel. Critik der reinen Vernunft, J.F. Hartknoch, Riga, 1781; 2. ed. modificada, 1787. Trad. fr. Alexandre J.L. Delamarre e François Marty, Critique de la raison pure. In: Kant, Emmanuel, Oeuvres philosophiques, v. 1. Paris, Gallimard, 1980, p. 7051470 .

KUHN, Thomas L. The structure of scientific revolutions, $1962 ; 2^{\mathrm{a}}$ ed. revista e aumentada, University of Chicago Press, 1970. Tr. fr., La Structure des Révolutions Scientifiques, Paris, Flammarion, 1972. 
LAGRANGE, Joseph Louis. Mécanique analytique. Paris, 1788; 2a ed., 1811.

LAKATOS, Imre. The methodology of scientific research programmes. (Philosophical papers, v. 1), John Worrall e Gregory Currie (ed.), Cambridge, Cambridge University Press, 1978.

LALANDE, André. La théorie de l'induction et de l'expérimentation. Paarais, Boivin, 1929. La raison et les normes. Paris, Hachette, 1948.

LE ROY, Edouard. Sur la logique de l'invention. Revue de métaphysique et de morale, mar. 1905.

MACH, Ernst. Die Mechanik in ibrer Entwicklung historisch-kritisch Dargellstell. Leipzig, 1883. Trad. fr., La mécanique. Exposé historique et critique de son développement. Paris, Hermann, 1904; reed. em 1923.

Beiträge zur Analyse der Empfindungen, Iena, 1886; Contributions to the the analysis of the sensations. Trad. C.M. Williams, Chicago, Open Court, 1897.

Court, 1898.

Popular scientifc lectures. Trad. T.J. McCormack, Chicago, Open

Erkenntnis and Irrtum. Leipzig, Barth, 1905; La connaissance et l'erreur, trad. fr. M. Dufour. Paris, Flammarion, 1908; 1922; Knowledge and error, trad. ingl. T.J. McCormack, P. Foulkes. Dordrecht, Reidel, 1976.

MEYERSON, Émile. De l'explication dans les sciences, 2 v. Paris, Payot, 1921.

Du cheminement de la pensée, 3 v. Paris, Alcan, 1931.

MILLER, Arthur I. Imagery in scientifc thought. Creating 20th Century Physics. Boston, Birkhauser, 1984.

PATY, Michel. Théorie et pratique de la connaissance chez Jean d'Alembert. Estrasburgo 2, 1977. Tese (doutorado em filosofia), Université des Sciences Humaines.

Einstein and Spinoza. In: Marjorie Grene and Debra Nails (orgs.), Spinoza and the sciences. Dordrecht, Reidel, 1986, p. 267-302.

Einstein philosophe. La physique comme pratique philosophique. Paris, Presses Universitaires de France, 1993.

Poincaré et le principe de relativité. In: Greffe, Jean-Louis; Heinzmann, Gerhard e Lorenz, Kuno (orgs.), Henri Poincaré. Science et philosophie. Science and philosophy. Wissenscchaft and Philosophie. Congrès international, Nancy, France, 1418 mai 1984, Berlin, Akademie Verlag; Paris, Albert Blanchard, 1996a, p. 101-143.

Le style d'Einstein, la nature du travail scientifique et le problème de la découverte. Revue Philosophique de Louvain, 94, p. 447-470, 3, ago. 1996b.

"Mathesis universalis" e inteligibilidad en Descartes. Trad. port. Martha Cecilia Bustamente. (Original fr.: "Mathesis universalis" et intelligibilité chez Descartes. In: Karine Chemla et al. orgs., Ceci n'est pas un Festschrift. Mélanges offerts à Imre Toth, 29.12.1996, no prelo). Campinas, Cadernos de História e Filosofia da Ciência, Série 3, v. 8, n. 1, p. 9-57, jan./jun. 1998 
PATY, Michel. La place des principes dans la physique mathématique au sens de Poincaré. In: Jan Sebestik e Antonia Soulez (orgs.), Actes du Colloque Philosophie et Science an tournant du siècle: Mach, Boltzmann, Poincaré et Duhem, Paris, 29 mai-1 ${ }^{\text {er }}$ juin 1995. Fundamenta philosophiae, Nancy, v. 3, n. 2, p. 75-90, 1998-1999.

no prelo.

[a]. Einstein, les quanta et le réel. Critique et construction théorique,

[b]. L'analogie mathématique au sens de Poincaré et sa fonction en physique. In: Durand-Richard, Marie-José (org.), Le statut de l'analogie dans la démarche scientifique, Éditions du CNRS, Paris, no prelo.

Poincaré, em preparo.

[c]. Empirisme et convention. Géométrie, physique et philosophie chez

PAUlhan, F. Psychologie de l'invention. Paris, 1901.

POINCARÉ, Henri. Mémoire (n. 5) soumis au Concours pour le Prix des Sciences Mathématiques. Archives, Dossier Poincaré, Académie des Sciences, $1^{\circ}$ de junho 1880a). A segunda parte, sobre as funções fuchsianas, foi publicada pela primeira vez em Acta Mathematica, 39, p. 58-93, 1923; republicado em Poincaré, 1913-1965, v. 1, p. 336-373.

Suppléments au mémoire soumis au Concours pour le Prix des Sciences Mathématiques, Académie des Sciences. Archives, Dossier Poincaré. (Sessões de 28 de junho, 6 de setembro, e manuscrito recebido em 20 de dezembro de 1880b. Publicado em Poincaré, 1996.

Du rôle de l'intuition et de la logique en mathématiques. In: Comptes rendus du Deuxième Congrès International des Mathématiciens. Paris, 1889, p. 115130. Republicado em Poincaré, 1913-1965, v. 11, p. 129-133. Também publicado sob o título: La logique et l'intuition dans la science mathématique et dans l'enseignement. L'Enseignement mathématique 1, p. 157-162, 1889. Republicado com modificações em Poincaré, 1905, capítulo 1.

POINCARÉ, Henri. Sur la nature du raisonnement mathématique. Revue de métaphysique et de morale 2, p. 371-384, 1894. Republicado em Poincaré, 1902, cap. 1.

Sur les rapports de l'analyse pure et de la physique mathématique, Acta mathematica 21, p. 331-341, 1897. Republicado em Poincaré, 1991, p. 17-30. Também publicado, com modificações, sob o título: Les rapports de l'analyse et de la physique mathématique, Revue générale des sciences pures et appliquées 8, p. 857-861, 1897; Republicado em Poincaré, 1905, capítulo 5: L'analyse et la physique, p. 103$113,1970$.

La science et l'hypothèse, 1902. Paris, Flammarion, 1968.

La valeur de la science, 1905. Paris, Flammarion, Paris, 1970.

. Science et méthode, 1908a. Paris, Flammarion, 1918.

dez. 1908b.

. Comment on invente. Le travail de l'inconscient, Le Matin. Paris, 24

L'invention mathématique. Bulletin de l'Institut Général de Psychologie, 
ano 8, n. 3, p. 175-196, 1908c. Conferência pronunciada na Sociedade de Psicologia de Paris. Igualmente, L'enseignement mathématique, 10, p. 359-371; republicado em Poincaré, 1908a, éd. 1918, p. 43-63.

. Le choix des faits, 1908d. The Monist, p. 231-232, 1909. Publicado em Poincaré, 1908a, livro 1, cap. 1, ed. 1918, p. 16-18.

Analyse des travaux scientifiques de Henri Poincaré faite par lui-même, 1913. Acta Mathematica, 38, p. 3-135, 1921. Republicado em 1916-1965, distribuído entre os diferentes volumes conforme os assuntos.

Oeuvres. Paris, Gauthier-Villars, 11 v., 1916-1965.

. L'analyse et la recherche. Seleção de textos e introdução de Girolamo

Ramunni. Paris, Hermann, 1991.

Trois suppléments sur la découverte des fonctions fuchsiennes. Three supplementary essays on the discovery of Fuchsian Functions. Jeremy J. Gray e Scott A. Walter (eds.). Berlim, Akademie Verlag; Paris, Albert Blanchard, 1996.

POPPER, Karl. Logik der Forschung. Zur Erkenntnisstheorie der modernen Naturwissenschaft. Viena, Springer Verlag, 1935. Reed. com acréscimos, 1959; 1968. Trad. ingl., The logic of scientific discovery, 1959; 1968. Trad. fr. por Nicole ThyssenRutten e Philippe Devaux, La logique de la découverte scientifique. Paris, Payot, 1973.

Objective knowledge, an evolutionary approach. Oxford, Clarendon Press, 1972. Trad. fr. parcial por C. Bastyns, La connaissance objective. Bruxelas, Complexe, 1978.

REICHENBACH, Hans. Experience and prediction. Chicago, University of Chicago Press, 1938.

REY, Abel. La théorie de la physique chez les physiciens contemporains. Paris, Alcan, 1907. La philosophie moderne. Paris, Flammarion, 1911.

RIBOT, Théodule. Essai sur l'imagination créatrice. Paris, 1900.

SPINOZA, Baruch. Court Traité, 1656. In: Spinoza, Oeuvres. Charles Appuhn (ed. e trad.), v. 1. Paris, Garnier-Flammarion, 1964.

RESUMO - POINCARÉ e Einstein baseiam sua concepção da descoberta e da invenção científicas como um processo criador sobre a "livre escolha" de conceitos e idéias teóricas por parte do pensamento. Essa "liberdade lógica" com relação aos dados factuais se estabelece sobre a crítica humana da indução, sobre a recusa do empirismo puro e sobre uma concepção da inteligibilidade racional tributária de Kant, ao mesmo tempo que sobre a crítica do apriorismo kantiano. Sublinhando a proximidade de suas convicções a esse respeito, apesar de suas concepções filosóficas divergentes sob outros aspectos (convencionalismo de Poincaré, realismo crítico de Einstein), examinamos como esse traço central das epistemologias desses dois cientistas-filósofos se situa em comparação com outros pensadores, do passado e de sua época, e como foi possibilitado pela evolução da matemática e da física no período imediatamente anterior. Procuramos relacionar 
esse traço aos processos de invenção científica tais como eles próprios os experimentaram em suas inovações criadoras.

ABSTRACT - POINCARÉ and Einstein based their conception of scientific discovery and invention as creative process on the "free choice" by thought of theoretical concepts and ideas. This "logical freedom" with respect to factual data is settled on the human critique of induction, on a refusal of pure empiricism, and on a conception of rational intelligibility indebted to Kant but combined at the same time with a critique of kantian apriorism. We emphasize the proximity of their convictions in this respect, despite differences in their philosophical ideas in other matters (Poincaré's conventionalism, Einstein's critical realism), and we compare this central feature of the two scientists-philosophers' epistemologies with others conceptions taken from thinkers of the past as well as contemporary to them. We consider also how this common interest and epistemological attitude had been made possible by the evolution of mathematics and physics in the immediately preceding period. We try to put these in connection with the processes of scientific invention as experienced by themselves in their creative innovations.

Michel Patyé orientador de pesquisa no CNRS, Equipe REHSEIS (UMR 7596), CNRS, e na Universidade Paris 7-Denis Diderot (37 rue Jacob, F-75006 Paris). Email: paty@paris7.jussieu.fr

Tradução de Sérgio Alcides. O original em francês - La création scientifique selon Poincaré et Einstein - encontra-se à disposição do leitor na sede do Instituto de Estudos Avançados da USP.

Uma primeira versão deste trabalho (La création scientifique selon Poincaré et Einstein, in Serfati, Michel (org.), La recherche de la vérité. Col. L'Écriture des Mathématiques, Paris, ACL-Éditions du Kangourou, 1999, p. 241-280) foi objeto de uma conferência pronunciada em língua portuguesa em 7 de novembro de 1997 por ocasião da criação da Cátedra Mário Schenberg no Instituto de Estudos Avançados da Universidade de São Paulo. 